Article

\title{
Environmentally Friendly Polyvinyl Alcohol-Alginate/ Bentonite Semi-Interpenetrating Polymer Network Nanocomposite Hydrogel Beads as an Efficient Adsorbent for the Removal of Methylene Blue from Aqueous Solution
}

\author{
Mona A. Aziz Aljar ${ }^{1}\left(\mathbb{D}\right.$, Suad Rashdan ${ }^{1}$ and Ahmed Abd El-Fattah ${ }^{1,2, *(D)}$ \\ 1 Department of Chemistry, College of Science, University of Bahrain, Sakhir P.O. Box 32038, Bahrain; \\ maljar@uob.edu.bh (M.A.A.A.); srashdan@uob.edu.bh (S.R.) \\ 2 Department of Materials Science, Institute of Graduate Studies and Research, Alexandria University, \\ Alexandria 21526, Egypt \\ * Correspondence: aahussein@uob.edu.bh or a_abdelfattah@alexu.edu.eg
}

Citation: Aljar, M.A.A.; Rashdan, S.; Abd El-Fattah, A. Environmentally Friendly Polyvinyl AlcoholAlginate/Bentonite Semi-Interpenetrating Polymer Network Nanocomposite Hydrogel Beads as an Efficient Adsorbent for the Removal of Methylene Blue from Aqueous Solution. Polymers 2021, 13, 4000. https://doi.org/10.3390/ polym 13224000

Academic Editor: Tansir Ahamad

Received: 3 November 2021

Accepted: 16 November 2021

Published: 19 November 2021

Publisher's Note: MDPI stays neutral with regard to jurisdictional claims in published maps and institutional affiliations.

Copyright: (c) 2021 by the authors Licensee MDPI, Basel, Switzerland. This article is an open access article distributed under the terms and conditions of the Creative Commons Attribution (CC BY) license (https:// creativecommons.org/licenses/by/ $4.0 /)$.

\begin{abstract}
Hazardous chemicals like toxic organic dyes are very harmful to the environment and their removal is quite challenging. Therefore there is a necessity to develop techniques, which are environment friendly, cost-effective and easily available in nature for water purification and remediation. The present research work is focused on the development ${ }^{\prime}$ and characterization of the ecofriendly semi-interpenetrating polymer network (semi-IPN) nanocomposite hydrogels composed of polyvinyl alcohol (PVA) and alginate (Alg) hydrogel beads incorporating natural bentonite (Bent) clay as a beneficial adsorbent for the removal of toxic methylene blue (MB) from aqueous solution. PVA-Alg/Bent nanocomposite hydrogel beads with different Bent content (0, 10, 20, and $30 \mathrm{wt} \%)$ were synthesized via external ionic gelation method. The designed porous and steady structure beads were characterized by the use of Fourier transform infrared spectroscopy (FTIR), energydispersive X-ray spectroscopy (EDX), and scanning electron microscopy (SEM). The performance of the beads as $\mathrm{MB}$ adsorbents was investigated by treating aqueous solutions in batch mode. The experimental results indicated that the incorporation of Bent (30 wt $\%)$ in the nanocomposite formulation sustained the porous structure, preserved water uptake, and increased MB removal efficiency by $230 \%$ compared to empty beads. Designed beads possessed higher affinity to MB at high $\mathrm{pH} 8,30^{\circ} \mathrm{C}$, and fitted well to pseudo-second-order kinetic model with a high correlation coefficient. Moreover, the designed beads had good stability and reusability as they exhibited excellent removal efficiency (90\%) after six consecutive adsorption-desorption cycles. The adsorption process was found be combination of both monolayer adsorption on homogeneous surface and multilayer adsorption on heterogeneous surface. The maximum adsorption capacity of the designed beads system as calculated by Langmuir isotherm was found to be $51.34 \mathrm{mg} / \mathrm{g}$, which is in good agreement with the reported clay-related adsorbents. The designed semi-IPN PVA-Alg/Bent nanocomposite hydrogel beads demonstrated good adsorbent properties and could be potentially used for MB removal from polluted water.
\end{abstract}

Keywords: alginate; polyvinyl alcohol; bentonite clay; nanocomposites hydrogel; cationic dyes; water remediation

\section{Introduction}

Methylene blue (MB) is a well-known cationic phenothiazine dye, with versatile industrial applications in the textile, leather, plastics, paper and cosmetics industry and also used as a biological stain and photosensitizer in photodynamic therapy [1-7]. However, $\mathrm{MB}$ is nonbiodegradable due to its complex aromatic structure, contributing to a prolonged toxicity [8-10]. Consequently, it is necessary to remove toxic MB dye from industrial effluents and wastewater for a more secure and sustainable environment $[11,12]$. 
Various conventional physicochemical techniques have been proposed and introduced for the purification of toxic dyes from water from including photocatalysis, chemical oxidation, ozonation, membrane filtration, coagulation and flocculation, as well as adsorption [13-17]. Among all of these techniques, the adsorption method is easily employed, fast and highly efficient [18-20]. Numerous different adsorbents have been synthesized such as activated carbons [21,22], porous ceramics [23,24], metal oxides [25], and polymeric hydrogels [26-30] for the remediation of contaminated water. Indeed, from both an environmental and industrial point of view, an ideal adsorbent should have large surface area, porous structure, available active functional sites, high mechanical stability and strength, as well as low cost and be eco-friendly [31,32].

In recent years, semi-interpenetrating polymer network (semi-IPN) biodegradable hydrogels consisting of linear polymer chains of one component entangled with other crosslinked polymer network have attracted wide attention as adsorbents for removal of pollutants from industrial water [33]. This is due to their desirable properties such as, biodegradability, biocompatibility, high elasticity and good mechanical strength [34]. In addition, during the removal process, the dye molecules can rapidly penetrate into the porous semi-IPN structures in solution and therefore, combine with the hydrophilic active site groups like hydroxyl $(-\mathrm{OH})$ and carboxyl $(-\mathrm{COOH})$ present on their surfaces $[26,35]$.

A striking candidate that constitutes the most investigated matrix in the preparation of semi-IPN hydrogels is sodium alginate (Alg), a naturally occurring anionic biopolymer obtained from brown algae. It has unique properties, including low cost, biodegradability, biocompatibility, and flexibility in hydrated environments. In addition, the ionized negatively-charged carboxylate $\left(-\mathrm{COO}^{-}\right)$groups of $\mathrm{Alg}$ are able to attract cationic $\mathrm{MB}$ from aqueous solutions [36-38]. Blending polyvinyl alcohol (PVA), which possesses high elasticity, and mechanical strength forms a semi-IPN hydrogel structure with an Alg hydrogel matrix with outstanding mechanical performance [39]. Despite that fact, several researchers have reported that semi-IPN PVA-Alg hydrogel has limited application in dye removal from wastewater owing to its relatively low adsorption capacity and selectivity $[37,38,40]$.

Nanoparticles based on clay minerals, have received extensive attention due to their remarkably low-cost, large abundance, high specific surface area, and good intrinsic adsorption characteristics $[11,23,31]$. Because of the anionic nature of the clay nanoparticles in aqueous media, a number of studies have been reported the efficacy of clay minerals for removing cationic dyes from wastewater [41,42]. Bentonite (Bent) is a naturally occurring clay that is composed tetrahedral Si layer and octahedral Al layer which are interlinked and contain reactive $-\mathrm{OH}$ groups. The charged layers are neutralized by the presence of cations like $\mathrm{Na}^{+}$and $\mathrm{K}^{+}$and the interlayer space holding some amount of water [43]. Owing to these exciting features, incorporating Bent nanoparticles into the semi-IPN PVA-Alg hydrogel matrices can significantly improve adsorption performance and further increase the mechanical stability of the hydrogel adsorbents [44,45].

The objective of the present research is to continue to explore the advantages of both ecofriendly polymeric hydrogel and natural nanoparticle-based materials. In particular, our aim is to synthesize and characterize biodegradable nanocomposite hydrogel, with enhanced mechanical stability and adsorption properties as well as understanding the adsorption mechanism in order to assess the best commercial formulations for industrial applications.

In this work, semi-IPN PVA-Alg/Bent nanocomposite hydrogel beads were prepared via external ionic gelation method and applied to the removal of toxic MB dye from aqueous solution. The structure, composition, morphology, and swelling of the assembled beads were investigated. Many factors affecting the $\mathrm{MB}$ adsorption from the aqueous solution by PVA-Alg/Bent nanocomposite hydrogel beads were studied in detail, including different Bent contents, $\mathrm{pH}$ values, contact time, initial $\mathrm{MB}$ concentration, different adsorbent dosage, temperature, and reusability. Further, adsorption kinetics, adsorption isotherms, and adsorption mechanism were analyzed. 


\section{Materials and Methods or Experimental}

\subsection{Materials}

Polyvinyl alcohol (PVA; molecular weight: 13,000-23,000 g/mol; $89 \mathrm{~mol} \%$ hydrolyzed), low viscosity alginate $(\mathrm{Alg})$ powder, calcium chloride $\left(\mathrm{CaCl}_{2}\right)$, hydrochloric acid $(\mathrm{HCl})$, sodium hydroxide $(\mathrm{NaOH})$, and methylene blue (MB; chemical formula: $\mathrm{C}_{16} \mathrm{H}_{18} \mathrm{~N}_{3} \mathrm{SCl}$, molecular weight: $319.85 \mathrm{~g} / \mathrm{mol}$, solubility in water: $40 \mathrm{~g} / \mathrm{L}, \lambda_{\max }=663 \mathrm{~nm}$, as shown in Figure 1a) were purchased from Sigma-Aldrich Co. (Munich, Germany) and used without further purification. Bentonite (Bent) clay nanoparticles (Bent; molecular weight: $180.1 \mathrm{~g} / \mathrm{mol}$; chemical formula: $\mathrm{H}_{2} \mathrm{Al}_{2} \mathrm{O}_{6} \mathrm{Si}$;), was obtained as a gift from Sphinx Milling Station Co. (Alexandria, Egypt). As shown in Figure 1b, an SEM image of Bent clay revealed a spherical nanosized particle morphology with average particle size of $26 \pm 1.43 \mathrm{~nm}$ and narrow size distribution ranging from $18 \pm 1.72 \mathrm{~nm}$ to $37 \pm 53 \mathrm{~nm}$ as determined by SEM image analysis software. The deionized water $(0.055 \mu \mathrm{S} / \mathrm{cm})$ was used in all experiments.
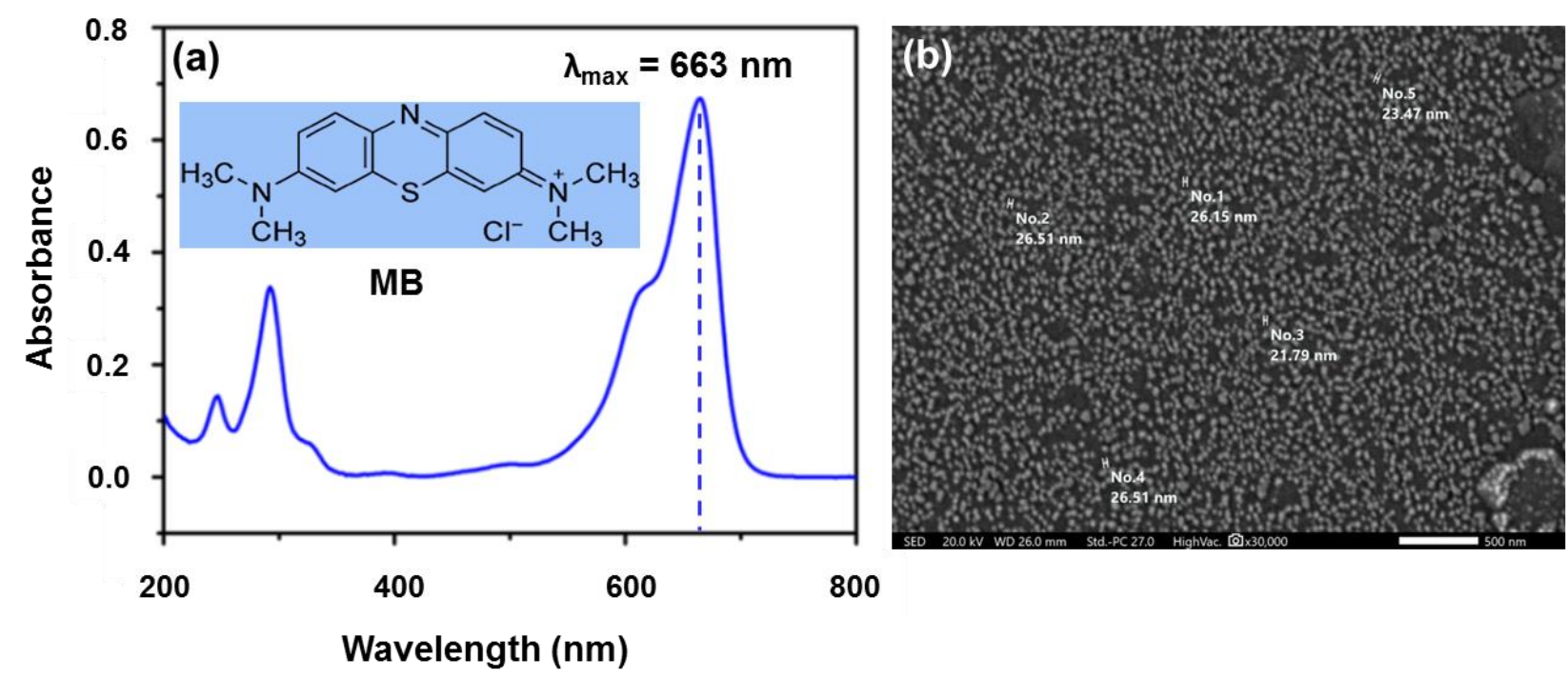

Figure 1. (a) UV/Vis spectrum of MB dye (the inset shows the chemical structure of MB) and (b) SEM micrograph of bentonite clay nanoparticles.

\subsection{Preparation of Semi-IPN Nanocomposite Hydrogel Beads}

PVA (2 g) and Alg (2 g) were dissolved in deionized water $(100 \mathrm{~mL})$ in a water bath at $90{ }^{\circ} \mathrm{C}$ under constant stirring at $350 \mathrm{rpm}$ for $2 \mathrm{~h}$ to achieve a homogeneous solution. After complete dissolution, the solution was stirred for an additional $1 \mathrm{~h}$ and cooled to room temperature. Then, a predetermined content of the Bent powder $(10,20$ and $30 \mathrm{wt} \%$ in relation to the polymers) was dispersed in the aqueous PVA-Alg solution via sonication at $40{ }^{\circ} \mathrm{C}$ for $30 \mathrm{~min}$, and the mixture was vigorously stirred for $1 \mathrm{~h}$ in a shaker. The obtained viscous suspension was slowly added dropwise by a syringe into the stirring $3 \%$ $(w / v) \mathrm{CaCl}_{2}$ solution to form semi-IPN nanocomposite hydrogel beads. To complete the gelation reaction, the beads were maintained in the $\mathrm{CaCl}_{2}$ solution overnight. Finally, the beads were filtered, washed three times with deionized water to remove any unreacted $\mathrm{CaCl}_{2}$, dried for $48 \mathrm{~h}$ at room temperature, and stored in a clean glass bottle for further characterization and adsorption study. Control hydrogel beads without Bent clay were prepared using the same previous steps.

\subsection{Characterization Methods}

\subsubsection{Fourier Transform Infrared Spectroscopy (FTIR)}

The chemical composition of the Bent, PVA-Alg control hydrogel and PVA-Alg/Bent nanocomposite hydrogel were analyzed by FTIR spectroscopy using a Spectrum Two FT-IR spectrometer (Perkin-Elmer, Waltham, MA, USA). The spectra were recorded throughout the wavenumber range from 4000 to $400 \mathrm{~cm}^{-1}$, at a resolution of $4 \mathrm{~cm}-1$ with 32 scans 
per sample. The sample was prepared using the $\mathrm{KBr}$ disc technique in which the sample ( $5 \mathrm{mg}$ ) was compressed with $\mathrm{KBr}$ powder $(200 \mathrm{mg}$ ) by hydraulic pressure to form a disk with a diameter of $12 \mathrm{~mm}$.

\subsubsection{Scanning Electron Microscopy (SEM)}

A scanning electron microscope (SEM) was used to assess the surface morphology of the desired beads. For this purpose, a JSM-5300 instrument (JEOL, Tokyo, Japan) was used, which was operated at $20 \mathrm{kV}$. Prior to SEM imaging, the samples were ultrasonically washed for $30 \mathrm{~s}$ and sputter-coated with gold to a thickness of $0.04 \mu \mathrm{m}$ in a sputter-coating unit (JFC 1100 E, JEOL).

\subsubsection{Energy-Dispersive X-ray Spectroscopy (EDX)}

Elemental composition of the Bent, PVA-Alg control hydrogel and PVA-Alg/Bent nanocomposite hydrogel was determined using an energy dispersive X-ray (EDX) microanalysis attachment on the SEM system. Analysis was performed on uncoated samples at $15 \mathrm{kV}$ for $60 \mathrm{~s}$.

\subsubsection{Swelling Behavior}

To estimate the swelling behavior of the beads, the dried beads were immersed in deionized water $(500 \mathrm{~mL})$ at different $\mathrm{pH}$ values $(3,7$, and 9$)$ for $5 \mathrm{~h}$ at room temperature until the beads reached equilibrium swelling. During this experiment, water was occasionally exchanged several times. The swollen beads were taken out of the aqueous solution at fixed time scheduled, surface wiped and weighted to obtain their wet weights $\left(\mathrm{W}_{\mathrm{w}}\right)$. Then they were dried at $40{ }^{\circ} \mathrm{C}$ in an oven until constant weight was achieved. After which, they were weighted again to determine their dry weights $\left(\mathrm{W}_{\mathrm{d}}\right)$. The average of five measurements was taken as the final result. The percentage of swelling ratio by each sample was calculated according to Equation (1) [46]:

$$
\text { Swelling ratio }(\%)=\left[\left(\mathrm{W}_{\mathrm{w}}-\mathrm{W}_{\mathrm{d}}\right) / \mathrm{W}_{\mathrm{d}}\right] \times 100
$$

\subsection{MB Adsorption Experiments}

The adsorption of MB from aqueous solution onto PVA-Alg/Bent nanocomposite hydrogel beads was systematically estimated. Before the adsorption experiments, a stock solution of MB (500 ppm) was prepared by dissolving an accurately weighed amount of $\mathrm{MB}$ powder in deionized water. The prepared stock solution was diluted to various $\mathrm{MB}$ concentrations of the same $\mathrm{pH}$ and absorbance was measured by using a UV/Vis spectrophotometer (Lambda 35, Perkin-Elmer) which recorded the characteristic absorption peak of $\mathrm{MB}$ at wavelength of $663 \mathrm{~nm}$. A calibration curve was constructed with reference to absorbance values of corresponding concentration of MB. The calibration curve equation was used to find the concentration of MB before and after adsorption. The adsorption experiments were studied by batch adsorption technique in which a certain amount of dried beads was added to a $100 \mathrm{~mL}$ Erlenmeyer flask containing MB solution $(50 \mathrm{~mL})$ of a certain concentration and placed in a mechanical water bath shaker at $150 \mathrm{rpm}$ for a predetermined period of time. Then, the supernatant was centrifuged and the concentration was measured by UV/Vis spectrophotometer. Effect of different Bent content (10, 20, and $30 \mathrm{wt} \%$ ), different $\mathrm{pH}(2-10)$, contact time (20-320 min), initial MB concentration (50-350 ppm), PVA-Alg/Bent dosage (0.1-2 g), and temperature $\left(20,30,40\right.$, and $\left.50{ }^{\circ} \mathrm{C}\right)$ have been explored to evaluate the performance of adsorbent beads. The equilibrium adsorption capacity, qe, $(\mathrm{mg} / \mathrm{g})$ of MB onto adsorbent beads as well as the removal percentage $(\%)$ were calculated from Equation (2) [47] and Equation (3) [48,49] respectively:

$$
\mathrm{q}_{\mathrm{e}}=\left(\mathrm{C}_{\mathrm{o}}-\mathrm{C}_{\mathrm{e}}\right) \times \mathrm{V} / \mathrm{m}
$$

$\operatorname{Removal}(\%)=\left[\left(\mathrm{C}_{\mathrm{o}}-\mathrm{C}_{\mathrm{e}}\right) / \mathrm{C}_{\mathrm{o}}\right] \times 100$ 
where $C_{o}$ and $C_{e}$ are the initial and equilibrium concentrations of $M B(m g / L)$, respectively, $\mathrm{m}$ is the adsorbent mass $(\mathrm{g})$ and $\mathrm{V}$ is the MB solution volume (L).

\subsection{Adsorbent Reusability Study}

The reusability of semi-IPN PVA-Alg/Bent adsorbent beads was determined in a repeated adsorption-desorption process. Adsorbent beads $(1.5 \mathrm{~g})$ were added to $\mathrm{MB}$ solution $(200 \mathrm{mg} / \mathrm{L}, 50 \mathrm{~mL})$ at $\mathrm{pH} 8$. The mixture was shaken in an orbital shaker incubator for $300 \mathrm{~min}$ at $30^{\circ} \mathrm{C}$. The saturated MB-loaded beads were collected out, washed thoroughly with deionized water, and dried for $48 \mathrm{~h}$ at room temperature. For the regeneration process, the dried beads were immersed in $\mathrm{HCl}$ solution $(0.1 \mathrm{M}, 50 \mathrm{~mL})$ and shaken at $150 \mathrm{rpm}$ for $30 \mathrm{~min}$, then separated from the solution, rinsed multiple times by deionized water till no more MB leached out, and finally dried for $48 \mathrm{~h}$ at room temperature for reuse. The regenerated beads were reused to conduct the same adsorption procedure at the same conditions. Six adsorption-desorption cycle tests, were carried out.

\subsection{Adsorbent Isotherms}

The adsorption mechanisms were studied by Freundlich and Langmuir isotherm models. The Freundlich isotherm adsorption formula is expressed in Equation (4) [50,51].

$$
\ln q_{e}=\ln K_{F}+\frac{1}{n} \ln C_{e}
$$

where $K_{F}\left[(\mathrm{mg} / \mathrm{g})(\mathrm{L} / \mathrm{mg})^{1 / \mathrm{n}}\right]$ and $n$ are the Freundlich constants, which represent the adsorption capacity and adsorption intensity, respectively. For favorable and multilayer cooperative adsorption, $1 / n$ value should be between 0 and 1 [51].

The Langmuir isotherm adsorption Equations (5) and (6) [50,51] were defined as follows:

$$
\begin{gathered}
\frac{C_{e}}{q_{e}}=\frac{1}{K_{L} q_{m}}+\frac{C_{e}}{q_{m}} \\
R_{L}=\frac{1}{1+K_{L} C_{o}}
\end{gathered}
$$

where $q_{m}(\mathrm{mg} / \mathrm{g})$ is the maximum adsorption capacity, $K_{L}(\mathrm{~L} / \mathrm{mg})$ is the Langmuir constant related to the affinity of the binding sites, and $R_{L}$ is the constant separation factor. $R_{\mathrm{L}}$ value between 0 and 1 states a favorable adsorption process [50].

\subsection{Adsorbent Kinetics}

Both pseudo-first and pseudo-second order kinetic models were adopted to estimate the adsorption kinetics of MB dye onto PVA-Alg/Bent nanocomposite hydrogel beads. The corresponding Equations (7) and (8) [50,51] displayed in their linear forms are as follows:

$$
\begin{gathered}
\ln \left(q_{e}-q_{t}\right)=\ln q_{e}-K_{1} t \\
\frac{\mathrm{t}}{q_{t}}=\frac{1}{K_{2} q_{e}^{2}}+\frac{1}{q_{e}} t
\end{gathered}
$$

where $q_{e}$ and $q_{t}(\mathrm{mg} / \mathrm{g})$ are the amounts of $\mathrm{MB}$ adsorbed at equilibrium and at time $t$, respectively. $K_{1}(1 / \mathrm{min})$ and $K_{2}(\mathrm{~g} / \mathrm{mg}$.min) are the rate constants of pseudo-first order and pseudo-second-order kinetics, respectively.

\subsection{Adsorbent Kinetics}

The significant differences between the data among the experimental groups were analyzed using a one-way ANOVA test followed by a Tukey's post-hoc test and a Student $t$-test. All data were represented as mean \pm standard deviation $(\mathrm{M} \pm \mathrm{SD})$ and each experiment being performed in at least five replicates. A $p$ value $<0.05$ was considered significant. 


\section{Results and Discussion}

\subsection{Design Rationale of the Nanocomposite Hydrogel Beads}

The semi-IPN PVA-Alg/Bent nanocomposite hydrogel beads were successfully prepared by external ionic gelation method with $\mathrm{Ca}^{2+}$ ions as crosslinkers $[44,47]$. The digital images of the wet and dry beads before and after adsorption of $\mathrm{MB}$ are displayed in Figure 2a,b,c. As shown in Figure 2a, the incorporation of Bent nanoparticles into the hydrogel beads was confirmed by the apparent beige color of the beads. The wet beads exhibited uniformly spherical shapes with a smooth surface and had a size of approximately $4 \mathrm{~mm}$ (Figure 2a). However, during air drying, the initial spherical shape of the beads was slightly changed, resulting in a rough surface morphology without a marked collapse on the surface, indicating an improved mechanical stability (Figure 2b). Indeed, the deformation in shape is inevitable when water was evaporated from the wet hydrogel beads throughout the drying process, causing volume shrinkage of hydrogel beads [52]. Figure $2 \mathrm{c}$ reveals black color of the beads indicated encapsulation of $\mathrm{MB}$ in the nanocomposite hydrogel beads.
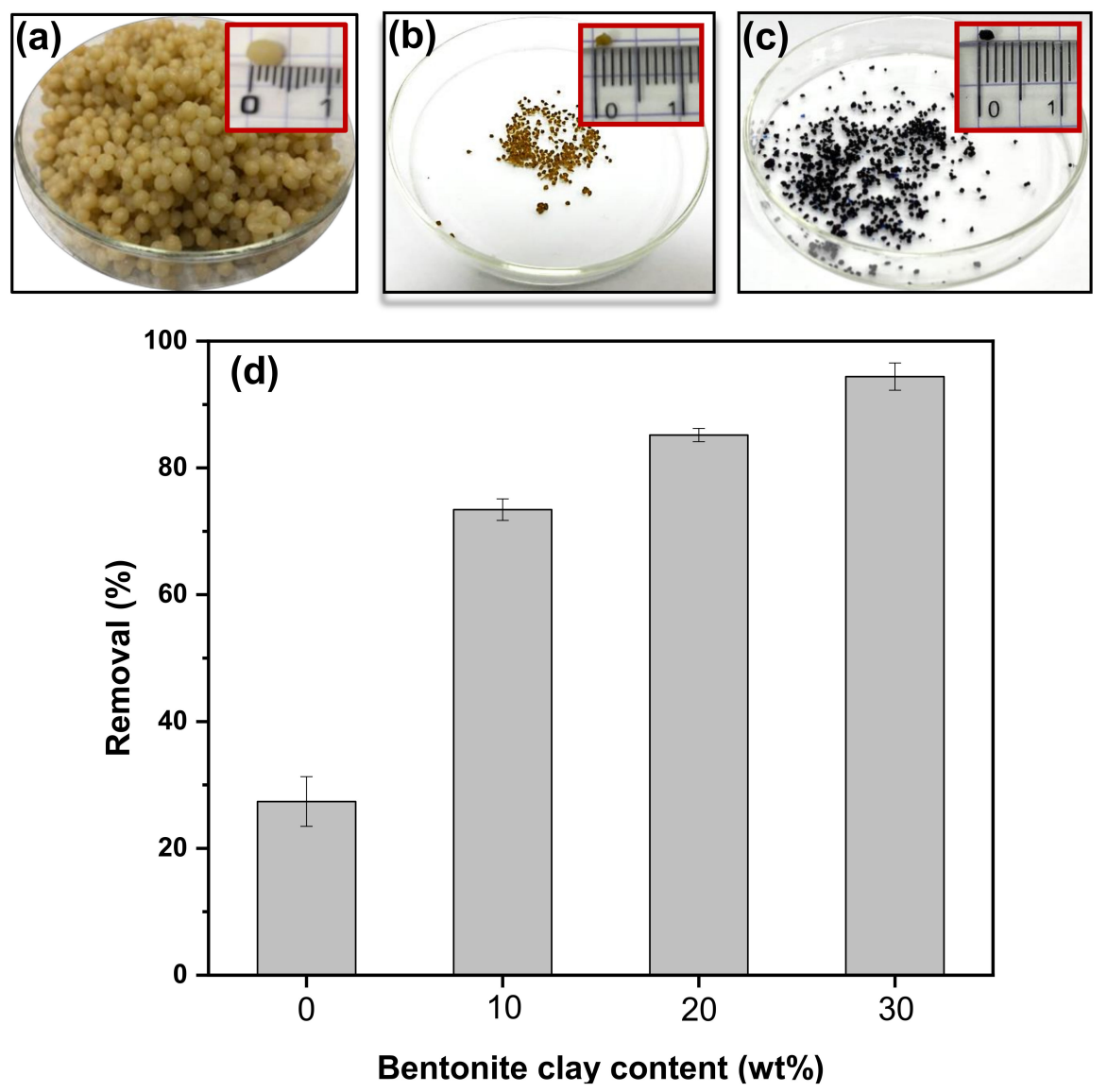

Figure 2. Semi-IPN PVA-Alg/Bent nanocomposite hydrogel beads (a) before drying (inset shows the size of wet beads), (b) after $48 \mathrm{~h}$ air drying (inset shows the size of dried beads), (c) after adsorption of MB dye (inset shows the size of MB-adsorbed beads), and (d) effect of bentonite content $(0$, $10,20,30 \mathrm{wt} \%)$ on the removal percentage of $\mathrm{MB}\left(\mathrm{C}_{\mathrm{o}}[\mathrm{MB}]=200 \mathrm{mg} / \mathrm{L}, \mathrm{V}=50 \mathrm{~mL}, \mathrm{pH}=8\right.$, beads dosage $=1.5 \mathrm{~g}, \mathrm{t}=300 \mathrm{~min}, \mathrm{~T}=30^{\circ} \mathrm{C}$ ).

In this work, the PVA: Alg weight ratio and the content of Bent nanoparticles were fixed at (1:1) and $30 \mathrm{wt} \%$, respectively. These values were selected because they represent an optimum performance of efficient adsorptive removal of MB dye and mechanical stability of the hydrogel beads [44]. To assess the adsorption ability of the designed nanocomposite hydrogel beads, preliminary adsorption tests were performed. As shown in Figure $2 \mathrm{~d}$, the control hydrogel beads had limited removal rate (28.53\%) for MB. Nevertheless, the removal rate of $\mathrm{MB}$ was significantly improved by increasing the content of Bent nanopar- 
ticles in the hydrogel beads. More specifically, the incorporation of $10 \mathrm{wt} \%, 20 \mathrm{wt} \%$, and $30 \mathrm{wt} \%$ Bent nanoparticles in the hydrogel beads increased the removal rate of MB dye by $165 \%, 190 \%$, and $230 \%$, respectively, compared to the control hydrogel beads. However, Bent contents exceeding the selected value were not used to avoid aggregation of Bent nanoparticles, which in turn may deteriorate the overall mechanical stability and beads strength [53,54]. After taking the factors of adsorption amount and mechanical strength into consideration, semi-IPN PVA-Alg/Bent (30 wt\%) nanocomposite hydrogel with appropriate $\mathrm{MB}$ removal percentage $(94.64 \%)$ and stiffness was selected for subsequent characterizations and adsorption study.

\subsection{Structure and Chemical Composition}

Figure 3 displays the FTIR spectra of the pristine Bent, semi-IPN PVA-Alg control hydrogel, and semi-IPN PVA-Alg/Bent nanocomposite hydrogel. Bent exhibits characteristic absorption peaks at 1054, 982, 3674, and $835 \mathrm{~cm}^{-1}$. The absorption peak at $1054 \mathrm{~cm}^{-1}$ is attributed to the stretching vibrations of $\mathrm{Si}-\mathrm{O}-\mathrm{Si}$ group, whereas the peak at $950 \mathrm{~cm}^{-1}$ is related to $\mathrm{Al}-\mathrm{OH}-\mathrm{Al}$ bending vibrations $[50,53]$. Besides, very weak bands at 3674 and $835 \mathrm{~cm}^{-1}$ are corresponding to $\mathrm{O}-\mathrm{H}$ and $\mathrm{Si}-\mathrm{O}$ stretching vibrations of silanol group of bent. The spectrum of the PVA-Alg hydrogel, shows a broad overlapped absorption band in the region of $3300-3400 \mathrm{~cm}^{-1}$ which is related the stretching vibration of $\mathrm{O}-\mathrm{H}$ of the PVA and Alg [44,47]. Absorption peaks in the area of $1635 \mathrm{~cm}^{-1}$ and $1428 \mathrm{~cm}^{-1}$ are due to asymmetric and symmetrical stretching vibrations of the $-\mathrm{COO}$ of $\mathrm{Alg}[44,55]$. The peak appeared at $2947 \mathrm{~cm}^{-1}$ was the typical stretching vibration for C-H in PVA. All the characteristic peaks of PVA, Alg, and Bent were observed in the FTIR spectrum of the nanocomposite hydrogel. In addition, the small shift in the position of the band near $1300 \mathrm{~cm}^{-1}$ would be related to the presence of hydrogen bonds between $\mathrm{O}-\mathrm{H}$ groups of PVA and Alg or with Si-O groups of Bent $[44,53,55]$. These results suggested that the Bent clay had successfully incorporated in the PVA-Alg hydrogel polymer matrix.

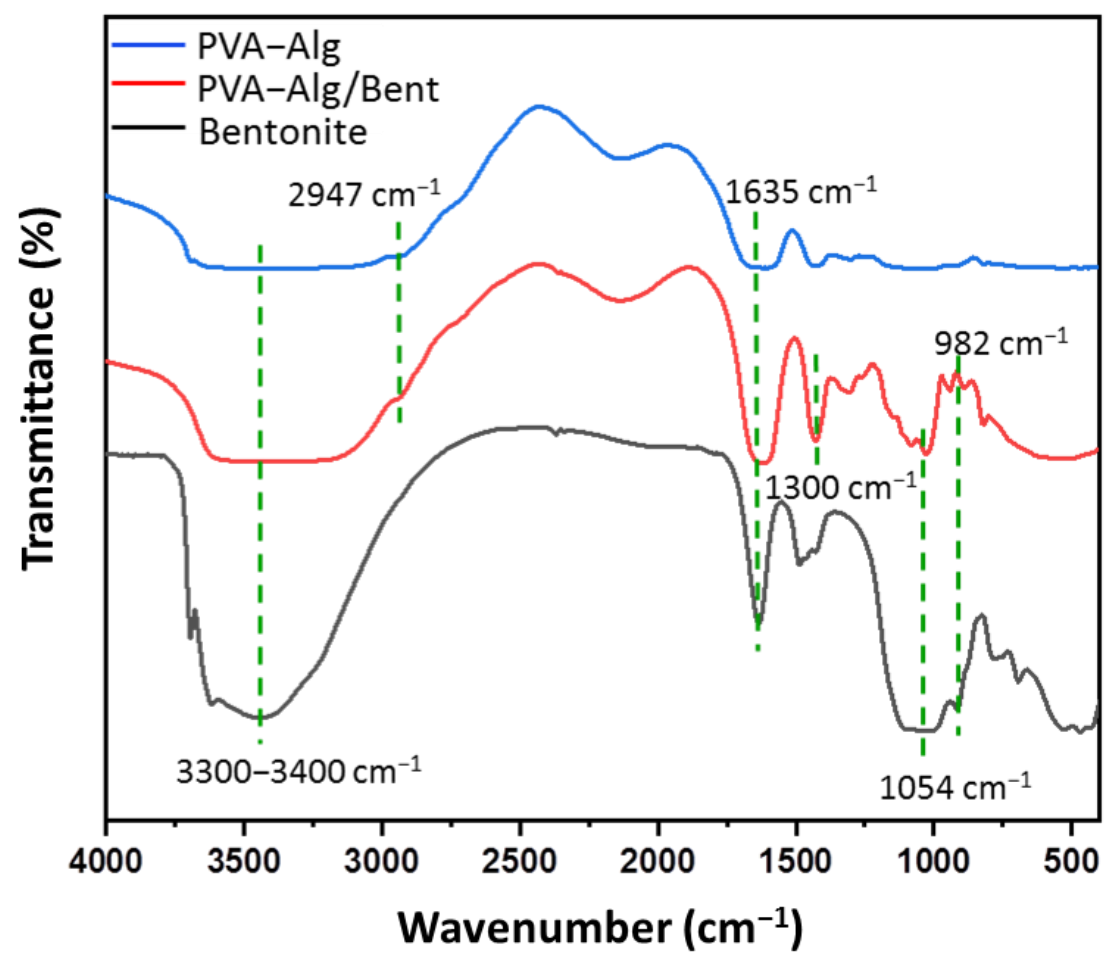

Figure 3. FTIR spectra of pristine Bent, semi-IPN PVA-Alg hydrogel and semi-IPN PVA-Alg/Bent nanocomposite hydrogel. 
The presence of Bent nanoparticles homogeneously distributed in the hydrogel matrix was further confirmed by EDX elemental analysis as shown in Figure 4. EDX spectrum of Bent clay (Figure $5 \mathrm{a}$ ) confirmed the presence of its main constituents such as $\mathrm{O}(51.70 \%)$, $\mathrm{Si}(21.89 \%), \mathrm{Al}(9.81 \%), \mathrm{Fe}(6.88 \%)$, and C $(4.61 \%)$ [50,56]. The main characteristic peaks attributed to $C(40.95 \%)$ and O $(52.19 \%)$ elements are detected in the EDX spectrum of control hydrogel (Figure $4 \mathrm{~b}$ ), which are due to the contribution of PVA and Alg component. It was worth noting that the peaks of $\mathrm{Si}, \mathrm{Al}$ and $\mathrm{Fe}$ elements can be clearly observed in the EDX spectrum (Figure 4c) of PVA-Alg/Bent nanocomposite hydrogel, indicated the successful incorporation of Bent nanoparticles on the hydrogel.
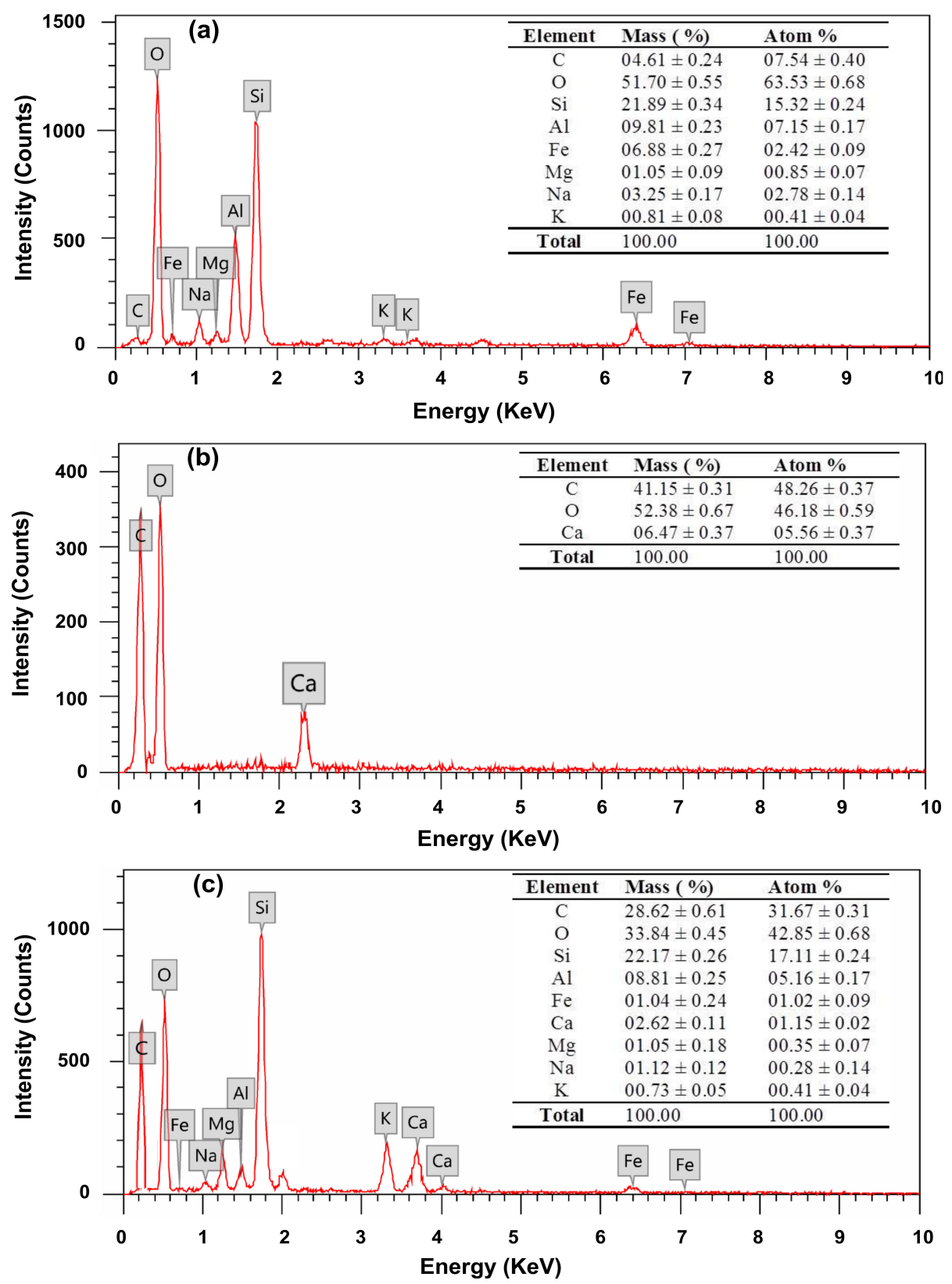

Figure 4. EDX spectra of (a) pristine bentonite clay (b) semi-IPN PVA-Alg control hydrogel, and (c) semi-IPN PVA-Alg/Bent nanocomposite hydrogel. The insets show the corresponding weight and atomic percentages of the elements present in the samples. 

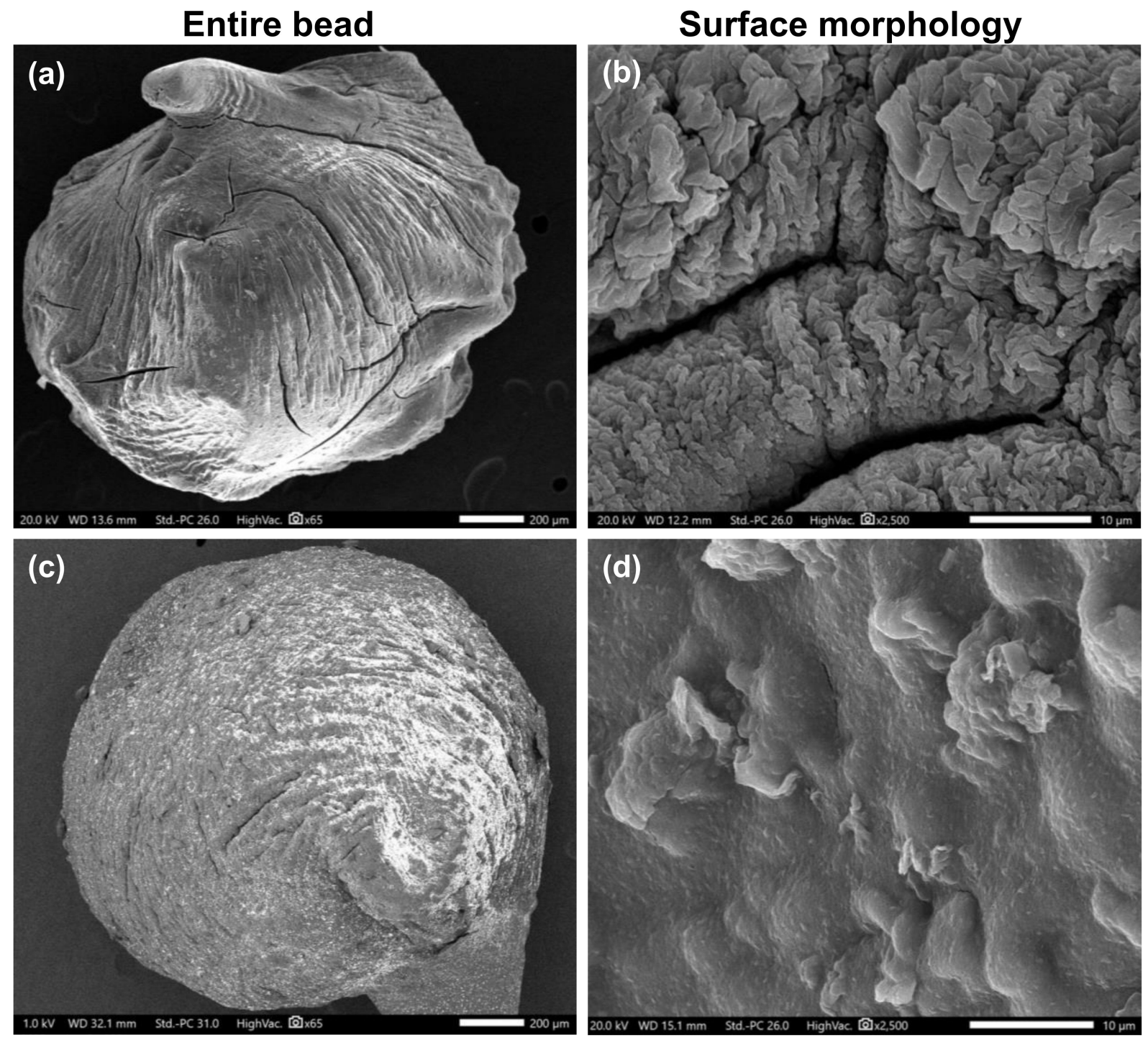

Figure 5. SEM micrographs of (a,b) semi-IPN PVA-Alg control hydrogel beads, and (c,d) semi-IPN PVA-Alg/Bent nanocomposite hydrogel beads.

\subsection{Morphological Observation}

Figure 6 presents the SEM micrographs of the dried entire beads and their surfaces for both control and nanocomposite hydrogels. SEM micrographs revealed a slight increase in the size of the nanocomposite bead (Figure 5a) compared to the unfilled bead (Figure 5c). Besides, both beads exhibited an irregular gully shape with some cracks and pores on the surface. However, as displayed in Figure $5 b, d$, the incorporation of Bent $(30 \mathrm{wt} \%)$ in the hydrogel resulted in a clear decrease in the size of the pores and the thickness of the cracks. Furthermore, the nanocomposite hydrogel showed uniform dispersion of the clay nanoparticles within the polymer matrix, leaving a relatively rough surface (Figure $5 \mathrm{~d}$ ). This structure will provide more contact sites and convenient diffusion channels, which may contribute to a better MB dye adsorption by PVA-Alg/Bent beads $[44,52,56]$. 

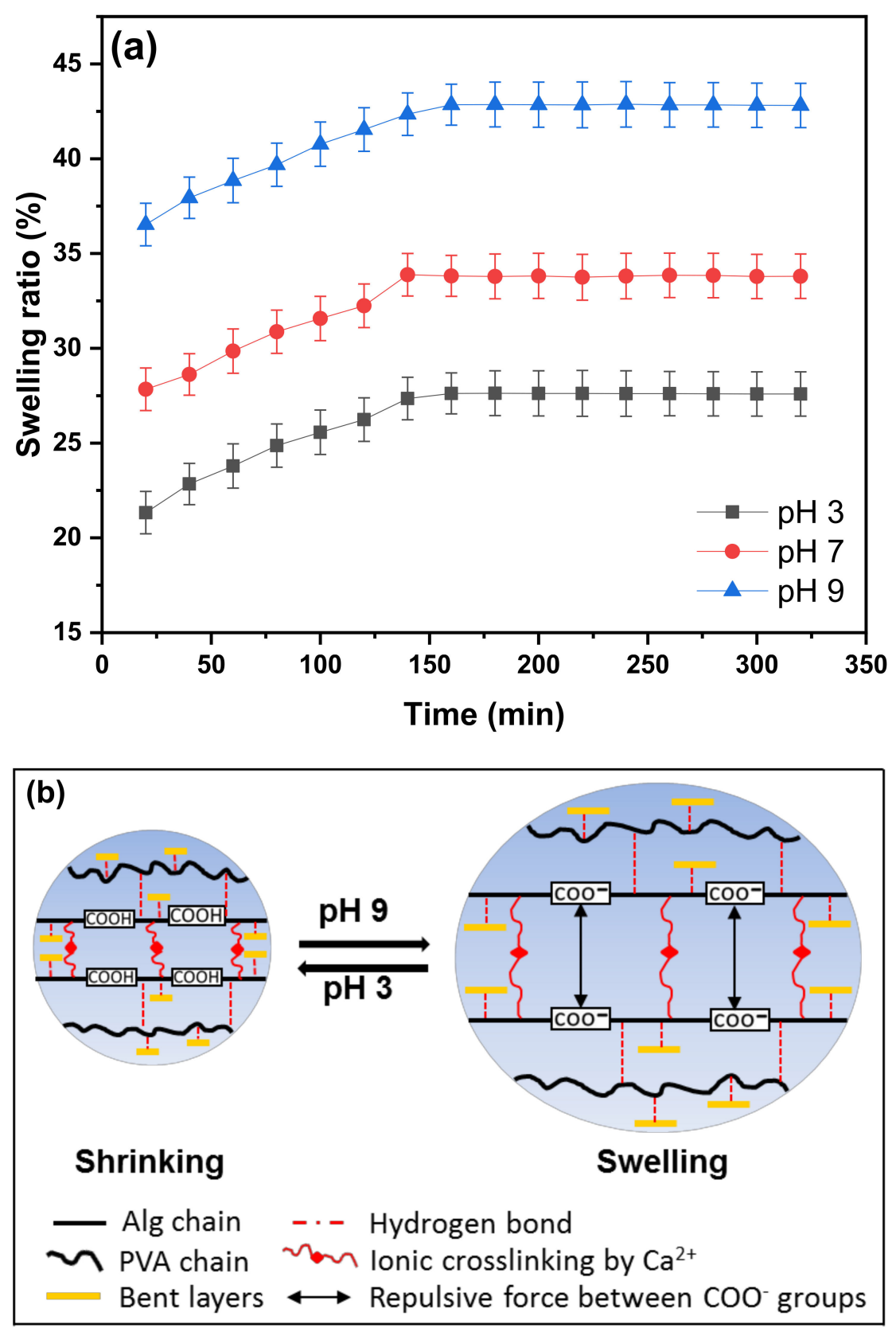

Figure 6. Swelling behavior of the semi-IPN PVA-Alg/Bent nanocomposite hydrogel beads at different $\mathrm{pH}$ values: (a) swelling ratio and (b) Schematic illustration.

\subsection{Swelling Behavior}

The swelling behavior of the semi-IPN PVA-Alg/Bent (30 wt\%) nanocomposite hydrogel beads in aqueous solution at different $\mathrm{pH}$ values is depicted in Figure 6. Clearly, all beads showed a similar tendency with different degrees of hydration. As can be seen from Figure $6 \mathrm{a}$, the swelling ratio enhanced slightly during the initial swelling stage (20-150 $\mathrm{min})$, and then turn into slower until reaching a plateau (150-320 min). One reasonable explanation for this observation was attributed to the presence of $-\mathrm{OH}$ groups on the polymer chains and clay surfaces that attract water molecules from the soaking medium, promoting their penetration into the gel-network, and eventually, elevating water uptake ability of the nanocomposite beads [56,57]. Moreover, hydrogel beads exhibited obvious $\mathrm{pH}$-dependent swelling behavior, where the water uptake of the beads increased significantly with increasing $\mathrm{pH}$ of the solution. More specifically, at $150 \mathrm{~min}$, the swelling rate increased gently within $\mathrm{pH} 3-7$ (from $25.5-30.2 \%$ ) and increased speedily in the range 
of pH 7-9 (from 30.2-40.6\%) indicating that the structure of the cross-linked hydrogel changed at different $\mathrm{pH}$ values (Figure $6 \mathrm{~b}$ ). The low swelling capacity at acidic solution $(\mathrm{pH} 3)$ can be due to the protonation of $-\mathrm{COO}^{-}$to $-\mathrm{COOH}$ groups of the hydrogel matrix. Consequently, the beads existed in collapsed state via the hydrophobic interaction, lead to more rigid gel-networks structure, which restricted traversing of water $[44,51,57]$. In neutral and alkaline solution ( $\mathrm{pH} 9)$, some of the $-\mathrm{COOH}$ groups in the hydrogel ionized to $-\mathrm{COO}^{-}$, which establishing repulsions between the negatively charged chains, facilitating the expansion of hydrogel and thus enhancing the swelling rate [51,57].

\subsection{Adsorption Studies of $M B$}

To study the suitability of the designed semi-IPN PVA-Alg/Bent nanocomposite hydrogel beads as adsorbent for $\mathrm{MB}$ dye, adsorption experiments were first conducted utilizing a batch experimental setup. The influences of various parameters on adsorption behaviors of the beads, such as $\mathrm{pH}$, contact time, initial dye concentration, beads dosage and temperature, were explored.

\subsubsection{Effect of Solution $\mathrm{pH}$}

The $\mathrm{pH}$ of dye solution is the most vital parameter controlling the efficiency of dye adsorption process [57]. The effect of solution $\mathrm{pH}$ on the adsorption capacity and removal percentage of MB dye by the nanocomposite hydrogel beads is illustrated in Figure 7a. As the $\mathrm{pH}$ increased from 2 to 5 , the adsorption capacity of $\mathrm{MB}$ was low and kept roughly constant, however, raised significantly within the $\mathrm{pH}$ range from 5 to 8 , and finally decreased at $\mathrm{pH}$ values greater than 8 . The maximum percentage of dye removal $(94.64 \%)$ was achieved at $\mathrm{pH} 8$. As mentioned above, the $\mathrm{pH}$ of the dye solution may affect the ionization of functional groups on the designed nanocomposite hydrogel adsorbent, which worked as the active sites of the hydrogel adsorbent, in turn, governing the electrostatic attraction between the anions on the hydrogel matrix and the cation on the MB dye [51,53,58]. At acid conditions, the negative surface charges of the nanocomposite hydrogel adsorbent were reduced, which were undesirable for the removal of positively charged MB dye. At alkaline $\mathrm{pH} 8$, the surface negative charges of the hydrogel increased, which was favorable for the removal of $\mathrm{MB}$ due to the enhanced electrostatic attraction to the positively charged MB. Above $\mathrm{pH} 8$, the surface of the hydrogel exhibited negative electricity, which lessening the electrostatic attraction between $\mathrm{MB}$ and the hydrogel, consequently, causing smaller removal values $[55,58]$. 

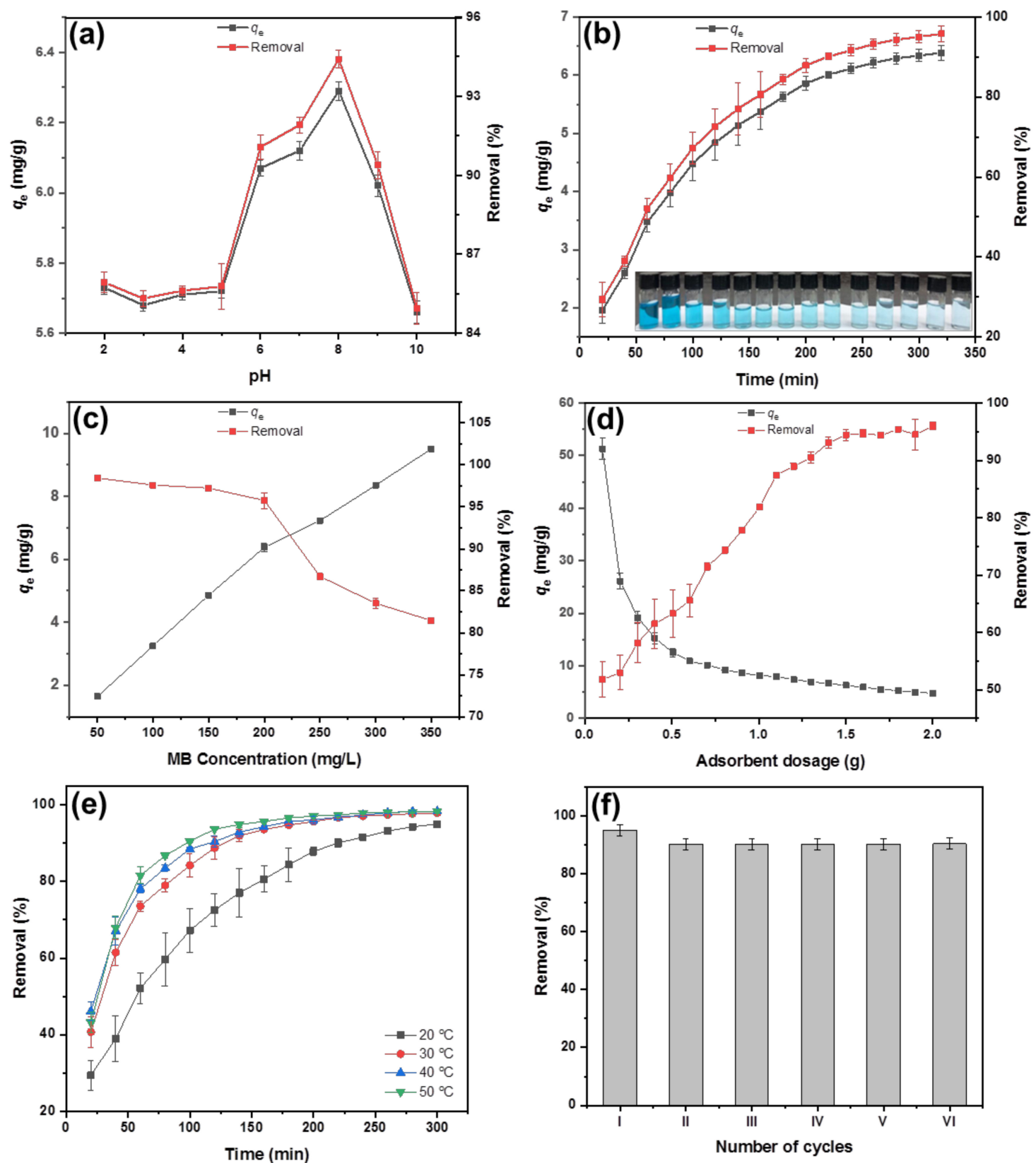

Figure 7. Effects of different factors on the adsorption capacity and removal percentage of MB onto the semi-IPN PVAAlg/Bent nanocomposite hydrogel beads: (a) $\mathrm{pH}\left(\mathrm{C}_{\mathrm{o}}[\mathrm{MB}]=200 \mathrm{mg} / \mathrm{L}, \mathrm{V}=50 \mathrm{~mL}\right.$, beads dosage $=1.5 \mathrm{~g}, \mathrm{pH}=8, \mathrm{t}=300 \mathrm{~min}$, $\left.\mathrm{T}=30{ }^{\circ} \mathrm{C}\right),(\mathbf{b})$ contact time $\left(\mathrm{C}_{\mathrm{o}}[\mathrm{MB}]=200 \mathrm{mg} / \mathrm{L}, \mathrm{V}=50 \mathrm{~mL}, \mathrm{pH}=8\right.$, beads dosage $\left.=1.5 \mathrm{~g}, \mathrm{~T}=30{ }^{\circ} \mathrm{C}\right),(\mathbf{c}) \mathrm{MB}$ initial concentration $\left(\mathrm{V}=50 \mathrm{~mL}, \mathrm{pH}=8\right.$, beads dosage $\left.=1.5 \mathrm{~g}, \mathrm{t}=300 \mathrm{~min}, \mathrm{~T}=30{ }^{\circ} \mathrm{C}\right),(\mathrm{d})$ adsorbent dosage $\left(\mathrm{C}_{\mathrm{o}}[\mathrm{MB}]=200 \mathrm{mg} / \mathrm{L}\right.$, $\left.\mathrm{V}=50 \mathrm{~mL}, \mathrm{pH}=8, \mathrm{t}=300 \mathrm{~min}, \mathrm{~T}=30^{\circ} \mathrm{C}\right),(\mathrm{e})$ temperature $\left(\mathrm{C}_{\mathrm{o}}[\mathrm{MB}]=200 \mathrm{mg} / \mathrm{L}, \mathrm{V}=50 \mathrm{~mL}, \mathrm{pH}=8\right.$, beads dosage $=1.5 \mathrm{~g}$, $\mathrm{t}=300 \mathrm{~min}$.), and (f) reusability $\left(\mathrm{C}_{\mathrm{o}}[\mathrm{MB}]=200 \mathrm{mg} / \mathrm{L}, \mathrm{V}=50 \mathrm{~mL}, \mathrm{pH}=8\right.$, beads dosage $\left.=1.5 \mathrm{~g}, \mathrm{t}=300 \mathrm{~min}, \mathrm{~T}=30^{\circ} \mathrm{C}\right)$.

\subsubsection{Effect of Contact Time}

Contact time is a significant factor that indicates whether the adsorbent removes the target contaminant to reach the equilibrium [55]. The variation of MO removal rate and adsorption capacity over contact time were shown in Figure $7 \mathrm{~b}$. It was found that the adsorption capacity, as well as removal percentage, were improved with increasing immersion contact time. A fast adsorption for the initial $60 \mathrm{~min}$ and a relatively slower adsorption after $60 \mathrm{~min}$ till $5 \mathrm{~h}$ were observed. At the same time, the color of the hydrogels became dark gradually, whereas the MB solution turned clear from an initial blue to completely transparent as shown in the inset of Figure $7 \mathrm{~b}$. These may be attributed to the 
filling of all the surface binding sites and diffusion of the MB molecules into pores of the designed beads. At the starting of adsorption process, there were plentiful active sites on the surface of the beads, which could combine with the MO molecules once they were added into dye solution $[57,58]$. Moreover, the high MB concentration in the solution provided the apparent driving force for $\mathrm{MB}$ adsorption supported by concentration gradient. In the later stage of the adsorption process, where the concentration of MB decreased, the adsorption sites on the surface of the beads tended to be saturated. Therefore, the diffusion and adsorption of MB molecules were reduced and hence the adsorption rate decreased continuously [59].

\subsubsection{Effect of Initial MB Concentration}

In batch adsorption, the initial concentration of the MB molecules is the main driving force offsetting the mass diffusion resistance force [56]. Figure 7c shows the influence of the initial concentration of $\mathrm{MB}$ on adsorption capacity and removal percentage of $\mathrm{MB}$. It could be noticed that the dye adsorption capacity increased with increasing initial $\mathrm{MB}$ concentration while the removal percentage declined. For instance, when the initial concentration of MB was 50, 200 and $300 \mathrm{mg} / \mathrm{L}$, the removal rate of beads was about 97, 85 and $69 \%$, respectively. This indicated that at a lower concentration of $\mathrm{MB}$, nanocomposite hydrogel beads had an abundance of adsorption active sites leading to a high adsorption for the majority of MB molecules [60]. However, saturation of adsorption sites would be established with further increases in the MB concentration, and adsorption became difficult since the increased numbers of MO molecules attached to the surface of the beads would repel free MO molecules [58-60].

\subsubsection{Effect of Adsorbent Dosage}

Adsorbent dosage is another key factor in the dye adsorption system for maximizing the cost efficiency and benefits of adsorbents [60]. Figure 7d illustrates the effects of adsorbent dosage on the MB adsorption capacity and removal percentage. When $0.1 \mathrm{~g}$ of the nanocomposite beads was applied, the MB adsorption capacity was $50 \mathrm{mg} / \mathrm{g}$, constituting a removal percentage of $54 \%$. With increasing beads dosage above $0.1 \mathrm{~g}$, the adsorption capacity decreased, but the dye removal percentage increased gradually, eventually reaching an equilibrium at a maximum value of $94.64 \%$ on using beads dosage of $1.5 \mathrm{~g}$. This is because the concentration of dye in the solution was fixed, so excessive adsorbent dosage caused the active sites of the adsorbent to compete, resulting in a decrease in the amount of dye adsorbed per unit surface area $[59,60]$. Accordingly, the optimal beads dosage for $\mathrm{MB}$ removal was set as $1.5 \mathrm{~g}$.

\subsubsection{Effect of Temperature}

The influence of temperature on the removal rate is an important factor to investigate dye adsorption in industrial wastewater at different temperatures $[55,58]$. The dependence of the $\mathrm{MB}$ removal percentage on the temperature was examined at various temperatures ranging from $20-50{ }^{\circ} \mathrm{C}$ as presented in Figure 7e. Obviously, the removal percentage increased as the temperature rises from 20 to $30^{\circ} \mathrm{C}$. More specifically, the removal percentage reached $95 \%$ after $200 \mathrm{~min}$ at $30{ }^{\circ} \mathrm{C}$, while it took $300 \mathrm{~min}$ to reach $90 \%$ at $20^{\circ} \mathrm{C}$. However, the removal percentage of $\mathrm{MB}$ at $40{ }^{\circ} \mathrm{C}$ and $50{ }^{\circ} \mathrm{C}$ revealed insignificant improvement compared with that at $30^{\circ} \mathrm{C}$. This finding was attributed to the increased mobility of the MB molecules at high temperature, which enhanced the MB molecules quickly get into the interior of hydrogel beads, resulting in an improvement of the removal percentage [57,61]. This behavior confirmed that the adsorption of dyes has an endothermic nature [61]. Hence, $30{ }^{\circ} \mathrm{C}$ was chosen as the optimum solution temperature.

\subsubsection{Reusability of Adsorbent}

For acceptance of a system at industrial scale, the system should be economically feasible and repetitive. The reusability performance of adsorbent determines the feasibility of 
large-scale practical application [48,49]. The prepared semi-IPN PVA-Alg/Bent nanocomposite beads can be quickly separated from solution by simple separation technology, which provides the possibility for subsequent desorption and reuse. The nanocomposite beads for the dyes are reused for six cycles, after washing with $0.1 \mathrm{M} \mathrm{HCl}$ solution as the eluent. The reutilization was determined by the sorption-desorption cycles of the beads. As shown in Figure $7 \mathrm{f}$, the beads had good adsorption effect on MB after one cycle of adsorptiondesorption tests, with a removal percentage of $94.32 \%$. As the number of cycles increases, the removal percentage can be maintained at a steady value of about $90 \%$, indicating that the adsorbent shows good structural stability [50]. The obtained results suggested that the nanocomposite beads have good application prospects because of the good adsorption performance, efficient reusability and low cost from using cheap, environment-friendly raw materials and a simple manufacturing process. Hence, the results mentioned above indicate the possibility of using the semi-IPN PVA-Alg/Bent nanocomposites hydrogel beads at an industrial scale for the removal of MB from industrial wastewaters.

\subsection{Adsorption Isotherm Study}

The isotherm models of Langmuir and Freundlich were employed to get more insights into the removal process of MB dye by semi-IPN PVA-Alg/Bent nanocomposite hydrogel beads. The Langmuir isotherm model is assumed to indicate affinity for homogenous monolayer adsorption, while the Freundlich isotherm model is used to recognize the adsorption of multiple adsorption layer surfaces [50,51]. Figure 8 displays the adsorption isotherms of the MB removal by the nanocomposite hydrogel beads. In the present study, both the Langmuir and Freundlich models showed very high $R^{2}$ values of 0.9932 and 0.9968 , respectively, which indicated the suitability of both models to describe the adsorption of MB on hydrogel beads [61]. Accordingly, the adsorption process was likely to comprises both monolayer adsorption on homogeneous surface and multilayer adsorption on heterogeneous surface. The results shown that, $R_{\mathrm{L}}$ values lay between 0.005 to $0.03\left(0<R_{L}<1\right)$ and $1 / \mathrm{n}$ was about $0.57(0<1 / n<1)$ as well as $q_{m}$ of $51.34 \mathrm{mg} / \mathrm{g}$ that confirmed the feasibility and favorability of the MB adsorption on the surface of the beads [62,63]. A comparison of $q_{\mathrm{m}}$ value for MB removal of the PVA-Alg/Bent nanocomposite hydrogel beads with other adsorbents is listed in Table 1, which clearly indicate the excellent adsorption capacity of the designed beads.
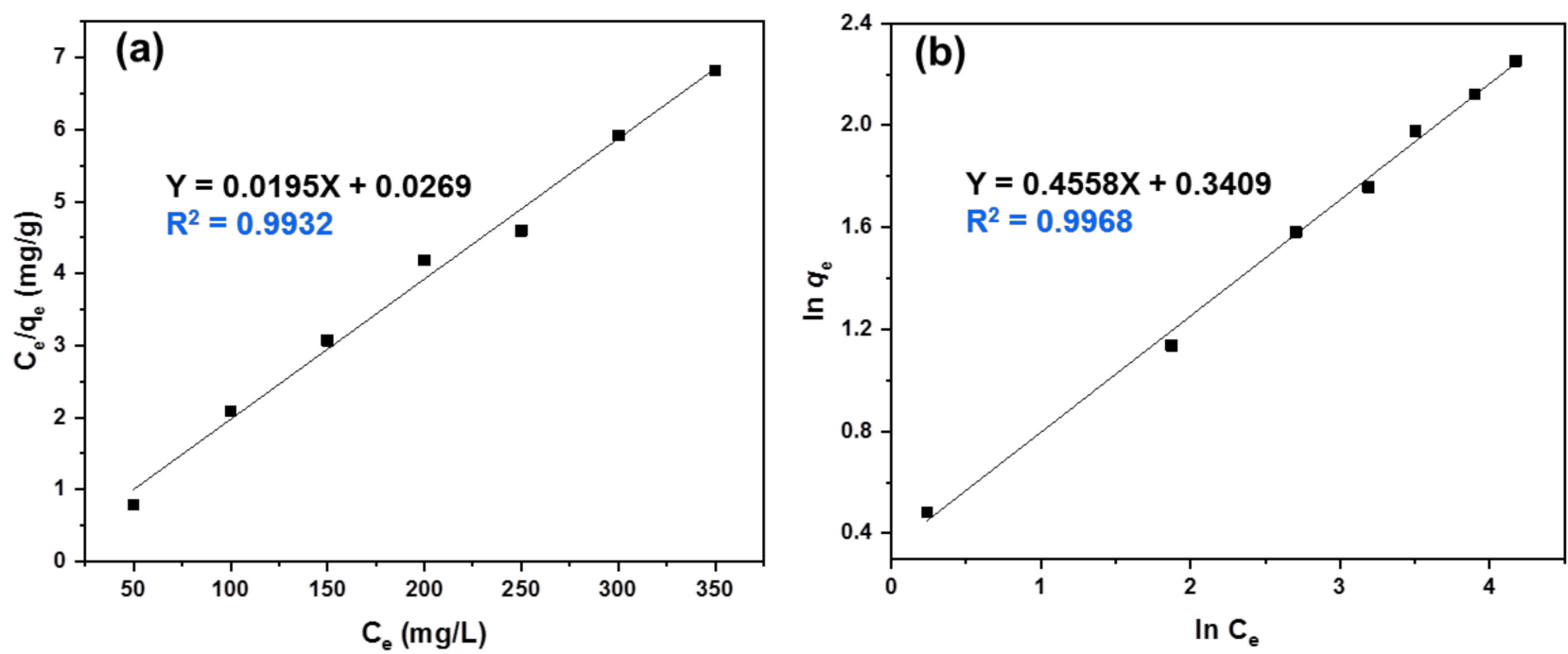

Figure 8. (a) The Langmuir adsorption isotherm and (b) Freundlich adsorption isotherm, for the adsorption of the MB onto the semi-IPN PVA-Alg/Bent nanocomposite hydrogel beads. 


\subsection{Adsorption Kinetics Study}

The kinetics of adsorption are an important index in defining the efficiency of sorption [58]. In this study, the kinetic behavior of MB sorption onto the beads was investigated using both the pseudo-first-order and pseudo-second-order kinetic models. Linear plots of $\ln \left(q_{e}-q_{t}\right)$ and $t / q_{t}$ versus contact time are shown in Figure $9 \mathrm{a}, \mathrm{b}$, respectively. It can be seen that the $\mathrm{R}^{2}$ value (0.9974) of the pseudo-second-order kinetic model was higher than that of the pseudo-first-order kinetic model (0.9615), hence, the pseudo-second-order kinetic model is more suitable for describing the adsorption behavior of MB onto the beads, and the main adsorption process of $\mathrm{MB}$ was dominated by a chemisorption mechanism. This result is in accord with previous reports on dye adsorption on polysaccharide-based adsorbents [64].
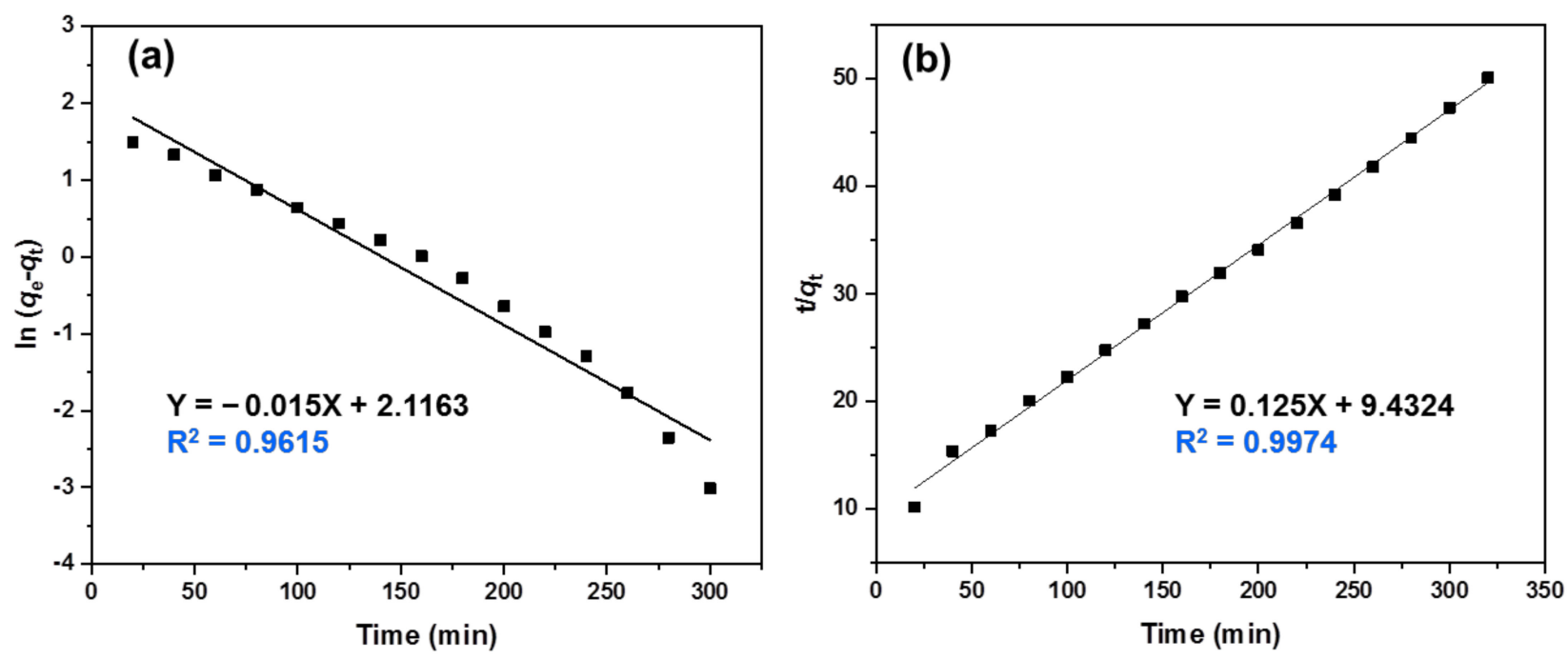

Figure 9. (a) The pseudo-first-order and (b) pseudo-second-order kinetic models for the adsorption of the MB onto the semi-IPN PVA-Alg/Bent nanocomposite hydrogel beads.

Table 1. Comparison of the designed semi-IPN PVA-Alg/Bent nanocomposite hydrogel beads with previously reported adsorbents for MB removal.

\begin{tabular}{ccc}
\hline Adsorbent & Maximum Adsorption Capacity (mg/g) & References \\
\hline Activated charcoal/ $\beta$-cyclodextrin/Alg hydrogel beads & 10.63 & {$[49]$} \\
PVA/cyclodextrin-modified poly(acrylic acid) hydrogel & 23.02 & {$[58]$} \\
Carboxymethyl cellulose (CMC)-based hydrogel & 25.00 & {$[65]$} \\
CMC/k-carrageenan/montmorillonite (MMT) beads & 12.50 & {$[66]$} \\
Graphene oxide (GO)/Fe $\mathrm{O}_{4} /$ chitosan nanocomposite & 30.10 & {$[67]$} \\
PVA/CMC/halloysite nanoclay membrane & 40.60 & {$[68]$} \\
Corn stalk/MMT composite hydrogel & 39.01 & {$[69]$} \\
GO/Fe $\mathrm{O}_{4} /$ Alg nanocomposite & 37.04 & {$[70]$} \\
Chitosan/sepiolite composite & 40.98 & {$[71]$} \\
PVA/Bent hydrogel & 27.90 & {$[72]$} \\
PVA-Alg/Bent nanocomposite hydrogel beads & 51.37 & This study \\
\hline
\end{tabular}

\subsection{Adsorption Mechanism of Cationic MB Dye}

Figure 10 displays an illustrative scheme for the proposed adsorption mechanism. As mentioned before, at alkaline $\mathrm{pH}$ values the negative surface charge of the PVA-Alg/Bent nanocomposite hydrogel gel adsorbent is increased due to the ionization of - $\mathrm{COOH}$ and $-\mathrm{SiOH}$ groups into $-\mathrm{COO}^{-}$and $-\mathrm{SiO}^{-}$, respectively. Thus, the removal of $\mathrm{MB}$ by the designed adsorbent is due to the electrostatic interactions between the positive charges on the iminium groups $(=\mathrm{N}+)$ present in the $\mathrm{MB}$ dye molecules and the abundant negative 
charges of the nanocomposite adsorbent. In addition, hydrogen bonding occurs between the $-\mathrm{OH}$ groups present in the adsorbent surface and nitrogen atom of MB [61,73].

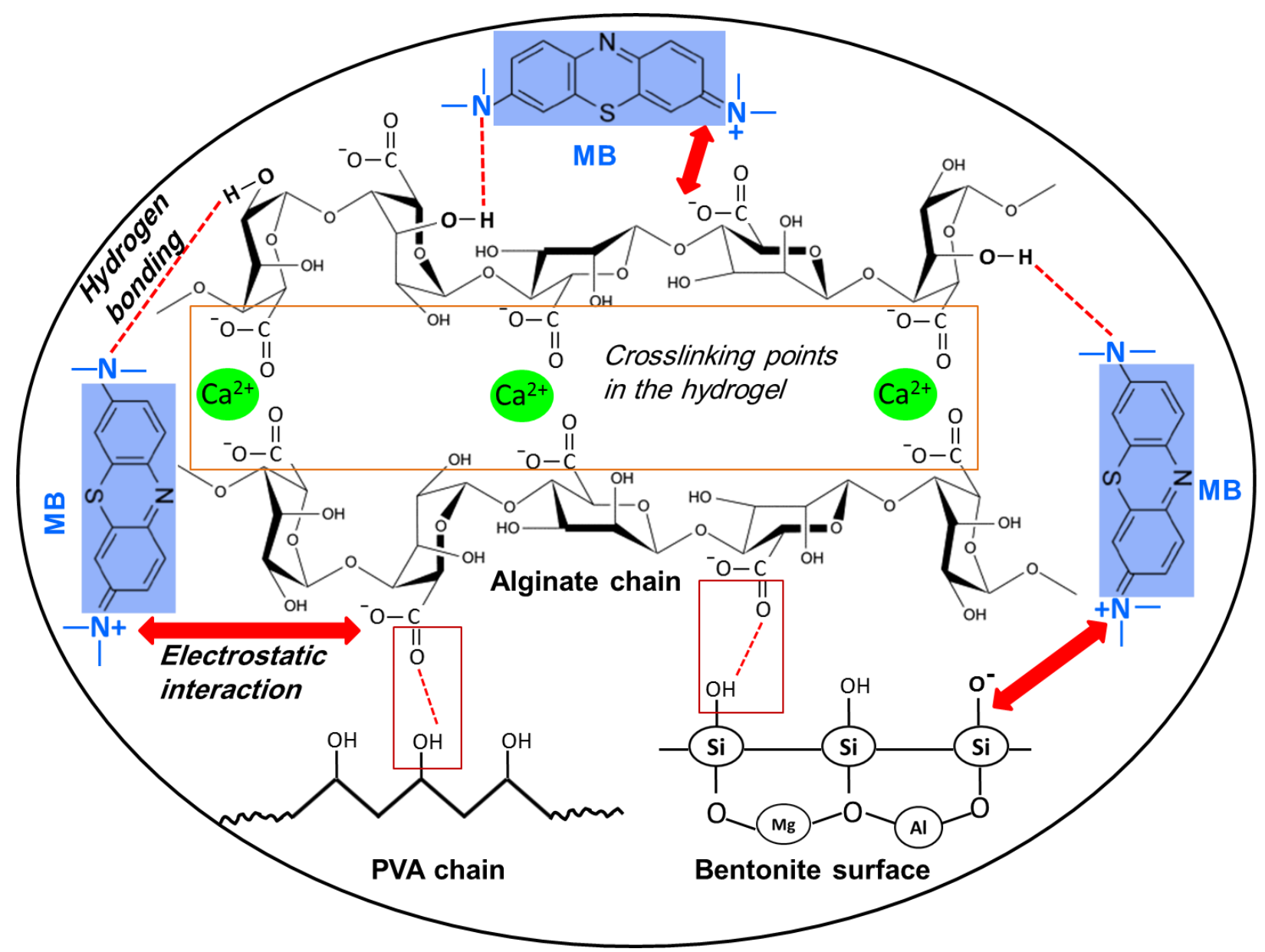

Figure 10. Proposed scheme indicating the possible interaction mechanism of the MB onto the PVA-Alg/Bent nanocomposite hydrogel beads.

\section{Conclusions}

In the present study, a semi-IPN PVA-Alg/Bent nanocomposite hydrogel was successfully developed as efficient adsorbent for the removal of MB dye from aqueous solution. The designed adsorbent beads possesses a porous structure, high specific surface area and net negative surface charge and provide many channels for the rapid adsorption of MB dye. Adsorbent beads had a good stability and reusability after six repeated cycles of adsorption and desorption. Moreover, the adsorbent beads showed outstanding MB removal efficiency with easy handling and extraction after adsorption, as well as eco-friendliness and low cost. Therefore, they could be suitable for the removal of other toxic cationic dyes and harmful pollutants from wastewater at an industrial scale.

Author Contributions: Conceptualization, A.A.E.-F.; Methodology, A.A.E.-F. and M.A.A.A.; Data analysis and interpretations, A.A.E.-F. and M.A.A.A.; Supervision, A.A.E.-F. and S.R.; Writingoriginal draft preparation, M.A.A.A.; Writing-review \& editing, A.A.E.-F. and S.R. All authors have read and agreed to the published version of the manuscript.

Funding: This research received no external funding.

Institutional Review Board Statement: Not applicable.

Informed Consent Statement: Not applicable.

Data Availability Statement: Not applicable. 
Conflicts of Interest: The authors declare no conflict of interest.

\section{References}

1. Eltaweil, A.S.; Mamdouh, I.M.; El-Monaem, E.M.A.; El-Subruiti, G.M. Highly Efficient Removal for Methylene Blue and Cu ${ }^{2+}$ onto UiO-66 Metal-Organic Framework/Carboxylated Graphene Oxide-Incorporated Sodium Alginate Beads. ACS Omega 2021, 6, 23528-23541. [CrossRef] [PubMed]

2. Liu, X.-J.; Li, M.-F.; Singh, S.K. Manganese-modified lignin biochar as adsorbent for removal of methylene blue. J. Mater. Res. Technol. 2021, 12, 1434-1445. [CrossRef]

3. Olusegun, S.J.; Freitas, E.T.F.; Lara, L.R.S.; Mohallem, N.D.S. Synergistic effect of a spinel ferrite on the adsorption capacity of nano bio-silica for the removal of methylene blue. Environ. Technol. 2021, 42, 2163-2176. [CrossRef] [PubMed]

4. Shen, Y.; Ni, W.-X.; Li, B. Porous Organic Polymer Synthesized by Green Diazo-Coupling Reaction for Adsorptive Removal of Methylene Blue. ACS Omega 2021, 6, 3202-3208. [CrossRef]

5. Silvestri, S.; Stefanello, N.; Sulkovski, A.A.; Foletto, E.L. Preparation of $\mathrm{TiO}_{2}$ supported on $\mathrm{MDF}$ biochar for simultaneous removal of methylene blue by adsorption and photocatalysis. J. Chem. Technol. Biotechnol. 2019, 95, 2723-2729. [CrossRef]

6. Shrestha, P.; Jha, M.K.; Ghimire, J.; Koirala, A.R.; Shrestha, R.M.; Sharma, R.K.; Pant, B.; Park, M.; Pant, H.R. Decoration of Zinc Oxide Nanorods into the Surface of Activated Carbon Obtained from Agricultural Waste for Effective Removal of Methylene Blue Dye. Materials 2020, 13, 5667. [CrossRef]

7. Arias, F.A.; Guevara, M.; Tene, T.; Angamarca, P.; Molina, R.; Valarezo, A.; Salguero, O.; Gomez, C.V.; Arias, M.; Caputi, L.S. The Adsorption of Methylene Blue on Eco-Friendly Reduced Graphene Oxide. Nanomaterials 2020, 10, 681. [CrossRef]

8. Nayl, A.A.; Abd-Elhamid, A.I.; Abu-Saied, M.A.; El-Shanshory, A.A.; Soliman, H.M.A.; Akl, M.A.; Aly, H.F. A novel method for highly effective removal and determination of binary cationic dyes in aqueous media using a cotton-graphene oxide composite. RSC Adv. 2020, 10, 7791-7802. [CrossRef]

9. Duhan, M.; Kaur, R. Nano-Structured Polyaniline as a Potential Adsorbent for Methylene Blue Dye Removal from Effluent. J. Compos. Sci. 2020, 5, 7. [CrossRef]

10. Alharthi, F.A.; Ali Alghamdi, A.; Alanazi, H.S.; Alsyahi, A.A.; Ahmad, N. Photocatalytic Degradation of the Light Sensitive Organic Dyes: Methylene Blue and Rose Bengal by Using Urea Derived g-C3N4/ZnO Nanocomposites. Catalysts 2020, 10, 1457. [CrossRef]

11. Palani, G.; Arputhalatha, A.; Kannan, K.; Lakkaboyana, S.; Hanafiah, M.; Kumar, V.; Marella, R. Current Trends in the Application of Nanomaterials for the Removal of Pollutants from Industrial Wastewater Treatment-A Review. Molecules 2021, $26,2799$. [CrossRef]

12. Norrahim, M.N.F.; Kasim, N.A.M.; Knight, V.F.; Misenan, M.S.M.; Janudin, N.; Shah, N.A.A.; Kasim, N.; Yusoff, W.Y.W.; Noor, S.A.M.; Jamal, S.H.; et al. Nanocellulose: A bioadsorbent for chemical contaminant remediation. RSC Adv. 2021, 11, 7347-7368. [CrossRef]

13. Mon, M.; Bruno, R.; Ferrando-Soria, J.; Armentano, D.; Pardo, E. Metal-organic framework technologies for water remediation: Towards a sustainable ecosystem. J. Mater. Chem. A 2018, 6, 4912-4947. [CrossRef]

14. Punia, P.; Bharti, M.K.; Chalia, S.; Dhar, R.; Ravelo, B.; Thakur, P.; Thakur, A. Recent advances in synthesis, characterization, and applications of nanoparticles for contaminated water treatment-A review. Ceram. Int. 2021, 47, 1526-1550. [CrossRef]

15. Taneez, M.; Hurel, C. A review on the potential uses of red mud as amendment for pollution control in environmental media. Environ. Sci. Pollut. Res. 2019, 26, 22106-22125. [CrossRef]

16. Karimi-Maleh, H.; Ranjbari, S.; Tanhaei, B.; Ayati, A.; Orooji, Y.; Alizadeh, M.; Karimi, F.; Salmanpour, S.; Rouhi, J.; Sillanpää, M.; et al. Novel 1-butyl-3-methylimidazolium bromide impregnated chitosan hydrogel beads nanostructure as an efficient nanobio-adsorbent for cationic dye removal: Kinetic study. Environ. Res. 2021, 195, 110809. [CrossRef]

17. Vafaei, M.A.; Shakeri, A.; Salehi, H.; Razavi, S.R.; Salari, N. The effect of nanosheets on polymer hydrogels performance in Rhodamine B dye removal by forward osmosis process. J. Water Process. Eng. 2021, 44, 102351. [CrossRef]

18. Chen, Y.; Lin, Z.; Hao, R.; Xu, H.; Huang, C. Rapid adsorption and reductive degradation of Naphthol Green B from aqueous solution by Polypyrrole/Attapulgite composites supported nanoscale zero-valent iron. J. Hazard. Mater. 2019, 371, 8-17. [CrossRef]

19. Garba, Z.N.; Zhou, W.; Lawan, I.; Xiao, W.; Zhang, M.; Wang, L.; Chen, L.; Yuan, Z. An overview of chlorophenols as con-taminants and their removal from wastewater by adsorption: A review. J. Environ. Manag. 2019, 241, 59-75. [CrossRef]

20. Tang, H.; Zhao, Y.; Shan, S.; Yang, X.; Liu, D.; Cui, F.; Xing, B. Theoretical insight into the adsorption of aromatic compounds on graphene oxide. Environ. Sci. Nano 2018, 5, 2357-2367. [CrossRef]

21. Wang, H.; Xu, J.; Liu, X.; Sheng, L. Preparation of straw activated carbon and its application in wastewater treatment: A review. J. Clean. Prod. 2021, 283, 124671. [CrossRef]

22. Bharath, G.; Hai, A.; Rambabu, K.; Savariraj, D.; Ibrahim, Y.; Banat, F. The fabrication of activated carbon and metal-carbide 2D framework-based asymmetric electrodes for the capacitive deionization of $\mathrm{Cr}$ (vi) ions toward industrial wastewater re-mediation. Environ. Sci. Water Res. Technol. 2020, 6, 351-361. [CrossRef]

23. Mouiya, M.; Bouazizi, A.; Abourriche, A.; Benhammou, A.; El Hafiane, Y.; Ouammou, M.; Abouliatim, Y.; Younssi, S.A.; Smith, A.; Hannache, H. Fabrication and characterization of a ceramic membrane from clay and banana peel powder: Application to industrial wastewater treatment. Mater. Chem. Phys. 2019, 227, 291-301. [CrossRef] 
24. Adam, M.R.; Salleh, N.M.; Othman, M.H.D.; Matsuura, T.; Ali, M.H.; Puteh, M.H.; Ismail, A.; Rahman, M.A.; Jaafar, J. The adsorptive removal of chromium (VI) in aqueous solution by novel natural zeolite based hollow fibre ceramic membrane. $J$. Environ. Manag. 2018, 224, 252-262. [CrossRef]

25. Nagpal, M.; Kakkar, R. Use of metal oxides for the adsorptive removal of toxic organic pollutants. Sep. Purif. Technol. 2019, 211, 522-539. [CrossRef]

26. Crini, G.; Torri, G.; Lichtfouse, E.; Kyzas, G.Z.; Wilson, L.D.; Morin-Crini, N. Dye removal by biosorption using cross-linked chitosan-based hydrogels. Environ. Chem. Lett. 2019, 17, 1645-1666. [CrossRef]

27. Pakdel, P.M.; Peighambardoust, S.J. Review on recent progress in chitosan-based hydrogels for wastewater treatment application. Carbohydr. Polym. 2018, 201, 264-279. [CrossRef]

28. Van Tran, V.; Park, D.; Lee, Y.-C. Hydrogel applications for adsorption of contaminants in water and wastewater treatment. Environ. Sci. Pollut. Res. 2018, 25, 24569-24599. [CrossRef]

29. Bandara, P.C.; Perez, J.V.D.; Nadres, E.T.; Nannapaneni, R.G.; Krakowiak, K.J.; Rodrigues, D.F. Graphene oxide nanocom-posite hydrogel beads for removal of selenium in contaminated water. ACS Appl. Polym. Mater. 2019, 1, 2668-2679. [CrossRef]

30. Horn, C.; Pospiech, D.; Allertz, P.J.; Müller, M.; Salchert, K.; Hommel, R. Chemical Design of Hydrogels with Immobilized Laccase for the Reduction of Persistent Trace Compounds in Wastewater. ACS Appl. Polym. Mater. 2021, 3, 2823-2834. [CrossRef]

31. Sadegh, H.; Ali, G.A.; Gupta, V.K.; Makhlouf, A.S.H.; Shahryari-Ghoshekandi, R.; Nadagouda, M.N.; Sillanpää, M.; Megiel, E. The role of nanomaterials as effective adsorbents and their applications in wastewater treatment. J. Nanostruct. Chem. 2017, 7, 1-14. [CrossRef]

32. Shalla, A.H.; Yaseen, Z.; Bhat, M.A.; Rangreez, T.A.; Maswal, M. Recent review for removal of metal ions by hydrogels. Sep. Sci. Technol. 2019, 54, 89-100. [CrossRef]

33. Ganguly, S.; Das, N.C. Water Uptake Kinetics and Control Release of Agrochemical Fertilizers from Nanoclay-Assisted Semiinterpenetrating Sodium Acrylate-Based Hydrogel. Polym. Technol. Eng. 2017, 56, 744-761. [CrossRef]

34. Ganguly, S.; Das, P.; Das, T.K.; Ghosh, S.; Das, S.; Bose, M.; Mondal, M.; Das, A.K.; Das, N.C. Acoustic cavitation assisted destratified clay tactoid reinforced in situ elastomer-mimetic semi-IPN hydrogel for catalytic and bactericidal application. Ultrason. Sonochem. 2020, 60, 104797. [CrossRef]

35. Fan, X.-M.; Yu, H.-Y.; Wang, D.-C.; Mao, Z.-H.; Yao, J.; Tam, K.C. Facile and Green Synthesis of Carboxylated Cellulose Nanocrystals as Efficient Adsorbents in Wastewater Treatments. ACS Sustain. Chem. Eng. 2019, 7, 18067-18075. [CrossRef]

36. Erfani, M.; Javanbakht, V. Methylene Blue removal from aqueous solution by a biocomposite synthesized from sodium alginate and wastes of oil extraction from almond peanut. Int. J. Biol. Macromol. 2018, 114, 244-255. [CrossRef]

37. Mokhena, T.C.; Jacobs, N.V.; Luyt, A.S. Nanofibrous alginate membrane coated with cellulose nanowhiskers for water puri-fication. Cellulose 2018, 25, 417-427. [CrossRef]

38. Luo, H.; Zeng, X.; Liao, P.; Rong, H.; Zhang, T.C.; Zhang, Z.J.; Meng, X. Phosphorus removal and recovery from water with macroporous bead adsorbent constituted of alginate-Zr4+ and PNIPAM-interpenetrated networks. Int. J. Biol. Macromol. 2019, 126, 1133-1144. [CrossRef]

39. Mok, C.F.; Ching, Y.C.; Muhamad, F.; Abu Osman, N.A.; Hai, N.D.; Hassan, C.R.C. Adsorption of Dyes Using Poly(vinyl alcohol) (PVA) and PVA-Based Polymer Composite Adsorbents: A Review. J. Polym. Environ. 2020, 28, 775-793. [CrossRef]

40. Ali, I.; Peng, C.; Naz, I.; Lin, D.; Saroj, D.P.; Ali, M. Development and application of novel bio-magnetic membrane capsules for the removal of the cationic dye malachite green in wastewater treatment. RSC Adv. 2019, 9, 3625-3646. [CrossRef]

41. Cavallaro, G.; Lazzara, G.; Rozhina, E.; Konnova, S.; Kryuchkova, M.; Khaertdinov, N.; Fakhrullin, R. Organic-nanoclay composite materials as removal agents for environmental decontamination. RSC Adv. 2019, 9, 40553-40564. [CrossRef]

42. Hosseini, S.A.; Daneshvar e Asl, S.; Vossoughi, M.; Simchi, A.; Sadrzadeh, M. Green Electrospun Membranes Based on Chitosan/Amino-Functionalized Nanoclay Composite Fibers for Cationic Dye Removal: Synthesis and Kinetic Studies. ACS Omega 2021, 6, 10816-10827. [CrossRef]

43. Fernandes, J.V.; Rodrigues, A.M.; Menezes, R.R.; Neves, G.D.A. Adsorption of Anionic Dye on the Acid-Functionalized Bentonite. Materials 2020, 13, 3600. [CrossRef]

44. Baigorria, E.; Cano, L.A.; Sanchez, L.M.; Alvarez, V.A.; Ollier, R.P. Bentonite-composite polyvinyl alcohol/alginate hydrogel beads: Preparation, characterization and their use as arsenic removal devices. Environ. Nanotechnol. Monit. Manag. 2020, 14, 100364. [CrossRef]

45. Zvulunov, Y.; Radian, A. Alginate Composites Reinforced with Polyelectrolytes and Clay for Improved Adsorption and Bioremediation of Formaldehyde from Water. ACS EST Water 2021, 1, 1837-1848. [CrossRef]

46. Abd El-Fattah, A.; Mansour, A. Viscoelasticity, mechanical properties, and in vitro biodegradation of injectable chitosan-poly (3-hydroxybutyrate-co-3-hydroxyvalerate)/nanohydroxyapatite composite hydrogel. Bull. Mater. Sci. 2018, 41, 1-10. [CrossRef]

47. Asadi, S.; Eris, S.; Azizian, S. Alginate-Based Hydrogel Beads as a Biocompatible and Efficient Adsorbent for Dye Removal from Aqueous Solutions. ACS Omega 2018, 3, 15140-15148. [CrossRef]

48. Hong, G.-B.; Yu, T.-J.; Lee, H.-C.; Ma, C.-M. Using Rice Bran Hydrogel Beads to Remove Dye from Aqueous Solutions. Sustainability 2021, 13, 5640. [CrossRef]

49. Yadav, S.; Asthana, A.; Chakraborty, R.; Jain, B.; Singh, A.K.; Carabineiro, S.A.C.; Susan, A.B.H. Cationic Dye Removal Using Novel Magnetic/Activated Charcoal/ $\beta$-Cyclodextrin/Alginate Polymer Nanocomposite. Nanomaterials 2020, 10, 170. [CrossRef] 
50. Ravi; Pandey, L.M. Enhanced adsorption capacity of designed bentonite and alginate beads for the effective removal of methylene blue. Appl. Clay Sci. 2019, 169, 102-111. [CrossRef]

51. Qi, X.; Wu, L.; Su, T.; Zhang, J.; Dong, W. Polysaccharide-based cationic hydrogels for dye adsorption. Colloids Surf. B Biointerfaces 2018, 170, 364-372. [CrossRef]

52. Merakchi, A.; Bettayeb, S.; Drouiche, N.; Adour, L.; Lounici, H. Cross-linking and modification of sodium alginate biopolymer for dye removal in aqueous solution. Polym. Bull. 2019, 76, 3535-3554. [CrossRef]

53. Oussalah, A.; Boukerroui, A. Alginate-bentonite beads for efficient adsorption of methylene blue dye. Euro-Mediterr. J. Environ. Integr. 2020, 5, 1-10. [CrossRef]

54. Wang, W.; Zhao, Y.; Bai, H.; Zhang, T.; Ibarra-Galvan, V.; Song, S. Methylene blue removal from water using the hydrogel beads of poly(vinyl alcohol)-sodium alginate-chitosan-montmorillonite. Carbohydr. Polym. 2018, 198, 518-528. [CrossRef]

55. Wu, N.; Niu, F.; Lang, W.; Xia, M. Highly efficient flame-retardant and low-smoke-toxicity poly (vinyl alco-hol)/alginate/ montmorillonite composite aerogels by two-step crosslinking strategy. Carbohydr. Polym. 2019, 221, 221-230. [CrossRef]

56. Fernandes, R.D.S.; de Moura, M.R.; Glenn, G.M.; Aouada, F.A. Thermal, microstructural, and spectroscopic analysis of Ca2+ alginate/clay nanocomposite hydrogel beads. J. Mol. Liq. 2018, 265, 327-336. [CrossRef]

57. Hu, T.; Liu, Q.; Gao, T.; Dong, K.; Wei, G.; Yao, J. Facile preparation of tannic acid-poly (vinyl alcohol)/sodium alginate hy-drogel beads for methylene blue removal from simulated solution. ACS Omega 2018, 3, 7523-7531. [CrossRef]

58. Hou, N.; Wang, R.; Wang, F.; Bai, J.; Zhou, J.; Zhang, L.; Hu, J.; Liu, S.; Jiao, T. Fabrication of Hydrogels via Host-Guest Polymers as Highly Efficient Organic Dye Adsorbents for Wastewater Treatment. ACS Omega 2020, 5, 5470-5479. [CrossRef]

59. Belhouchat, N.; Zaghouane-Boudiaf, H.; Viseras, C. Removal of anionic and cationic dyes from aqueous solution with activated organo-bentonite/sodium alginate encapsulated beads. Appl. Clay Sci. 2017, 135, 9-15. [CrossRef]

60. Su, T.; Wu, L.; Pan, X.; Zhang, C.; Shi, M.; Gao, R.; Qi, X.; Dong, W. Pullulan-derived nanocomposite hydrogels for wastewater remediation: Synthesis and characterization. J. Colloid Interface Sci. 2019, 542, 253-262. [CrossRef]

61. Zhang, Z.-H.; Xu, J.-Y.; Yang, X.-L. MXene/sodium alginate gel beads for adsorption of methylene blue. Mater. Chem. Phys. 2021, 260, 124123. [CrossRef]

62. Luo, J.; Fu, K.; Yu, D.; Hristovski, K.D.; Westerhoff, P.; Crittenden, J.C. Review of advances in engineering nanomaterial adsorbents for metal removal and recovery from water: Synthesis and microstructure impacts. ACS EST Eng. 2021, 1, 623-661. [CrossRef]

63. Luo, J.; Yu, D.; Hristovski, K.D.; Fu, K.; Shen, Y.; Westerhoff, P.; Crittenden, J.C. Critical Review of Advances in Engineering Nanomaterial Adsorbents for Metal Removal and Recovery from Water: Mechanism Identification and Engineering Design. Environ. Sci. Technol. 2021, 55, 4287-4304. [CrossRef] [PubMed]

64. Yu, D.; Wang, Y.; Wu, M.; Zhang, L.; Wang, L.; Ni, H. Surface functionalization of cellulose with hyperbranched polyamide for efficient adsorption of organic dyes and heavy metals. J. Clean. Prod. 2019, 232, 774-783. [CrossRef]

65. Capanema, N.S.; Mansur, A.A.; Mansur, H.S.; de Jesus, A.C.; Carvalho, S.M.; Chagas, P.; de Oliveira, L.C. Eco-friendly and biocompatible cross-linked Carboxymethyl cellulose hydrogels as adsorbents for the removal of organic dye pollutants for en-vironmental applications. Environ. Technol. 2018, 39, 2856-2872. [CrossRef]

66. Liu, C.; Omer, A.; Ouyang, X. Adsorptive removal of cationic methylene blue dye using carboxymethyl cellu-lose/kcarrageenan/activated montmorillonite composite beads: Isotherm and kinetic studies. Int. J. Biol. Macromol. 2018, 106, 823-833. [CrossRef]

67. Tran, H.V.; Bui, L.T.; Dinh, T.T.; Le, D.H.; Huynh, C.D.; Trinh, A.X. Graphene oxide/Fe3O4/chitosan nanocomposite: A recoverable and recyclable adsorbent for organic dyes removal. Application to methylene blue. Mater. Res. Express 2017, 4, 35701. [CrossRef]

68. Radoor, S.; Karayil, J.; Parameswaranpillai, J.; Siengchin, S. Adsorption of methylene blue dye from aqueous solution by a novel PVA/CMC/halloysite nanoclay bio composite: Characterization, kinetics, isotherm and antibacterial properties. J. Environ. Health Sci. Eng. 2020, 18, 1311-1327. [CrossRef]

69. Ma, D.; Zhu, B.; Cao, B.; Wang, J.; Zhang, J. Fabrication of the novel hydrogel based on waste corn stalk for removal of methylene blue dye from aqueous solution. Appl. Surf. Sci. 2017, 422, 944-952. [CrossRef]

70. Song, N.; Wu, X.L.; Zhong, S.; Lin, H.; Chen, J.R. Biocompatible G-Fe3O4/CA nanocomposites for the removal of methylene blue. J. Mol. Liq. 2015, 212, 63-69. [CrossRef]

71. Marrakchi, F.; Khanday, W.A.; Asif, M.; Hameed, B.H. Cross-linked chitosan/sepiolite composite for the adsorption of meth-ylene blue and reactive orange 16. Int. J. Biol. Macromol. 2016, 93, 1231-1239. [CrossRef]

72. Sanchez, L.M.; Ollier, R.P.; Alvarez, V.A. Sorption behavior of polyvinyl alcohol/bentonite hydrogels for dyes removal. J. Polym. Res. 2019, 26, 142. [CrossRef]

73. Jana, S.; Ray, J.; Mondal, B.; Tripathy, T. Efficient and selective removal of cationic organic dyes from their aqueous solutions by a nanocomposite hydrogel, katira gum-cl-poly(acrylic acid-co-N, N-dimethylacrylamide)@bentonite. Appl. Clay Sci. 2019, 173, 46-64. [CrossRef] 